\title{
Exposing the Origins of the Ebola Outbreak: Urging for a Shift in Response from Reactive to Proactive
}

\author{
Arooj Akhtar, Eyerusalem Befkadu, Paramita Basu*, Priyank Kumar* \\ Pharmaceutical and Biomedical Sciences, Touro College of Pharmacy, New York, USA \\ *Corresponding author: Paramita.basu@touro.edu; priyank.kumar3@touro.edu
}

Received November 12, 2014; Revised December 12, 2014; Accepted December 24, 2014

\begin{abstract}
On August 8, 2014, the World Health Organization established that the current Ebola virus disease (EVD) epidemic is a Public Health Emergency of International Concern (PHEIC), urging the global community to orchestrate their efforts to control the outbreak. As of November 12, 2014 the World Health Organization reported that at least 5,160 lives have been lost to the virus. We conducted a literature review in order to determine the underlying factors contributing to the emergence, rapid spread, and uncontrolled nature of the current virus outbreak, the first to display a distinct epicenter in West Africa. The global community's reaction to Ebola has been marked by fear. Fear of both the unknown nature of the virus, and knowing that we have made limited efforts in strengthening our arsenal of Ebola fighting treatment options. We explore novel treatment and precautionary approaches in an attempt to shift the response from reactive to proactive in our efforts to battle Ebola.
\end{abstract}

Keywords: Ebola Virus Disease (EVD), seasonal distribution, deforestation, socio-political infrastructure, micronutrient deficiency, vaccines, treatment

Cite This Article: Arooj Akhtar, Eyerusalem Befkadu, Paramita Basu, and Priyank Kumar, "Exposing the Origins of the Ebola Outbreak: Urging for a Shift in Response from Reactive to Proactive." American Journal of Infectious Diseases and Microbiology, vol. 2, no. 6A (2014): 1-18. doi:10.12691/ajidm-2-6A-1.

\section{Introduction}

Ebola is an aggressive pathogen that causes hemorrhagic fever syndrome in both humans and nonhuman primates, known as Ebola Virus Disease (EVD) [1]. Genus Ebolavirus is one of three members of the Filoviridae family (filovirus), along with genus Marburg virus and genus Cueva virus [2]. There are five identified subspecies of Ebolavirus. Four of the five have been known to cause diseases in humans. These are the Ebola virus (Zaire ebola virus), Sudan virus (Sudan ebola virus), Taï Forest virus (Taï Forest ebola virus, formerly Côte d'Ivoire ebola virus), and Bundibugyo virus (Bundibugyo ebola virus) [1]. The fifth, Reston virus (Reston ebola virus), known to cause disease in nonhuman primates, is also capable of infecting humans, but no illness or death in humans from this species has been reported to date [2]. The natural reservoir of Ebola virus remains unknown. However, based on evidence from similar viruses, researchers believe that the virus stems from a zoonotic reservoir, specifically the bats Hypsignathus monstrosus and Epomops franqueti and Myonycteris troquata are the most likely candidates [2,3]. Of these, M. torquata and H.monstrosus are found to be distributed across Guinea [3]. Part of common socio-cultural practice is to hunt and consume wild forest animals in West Africa, which has led to speculations involving the handling of bushmeat as a trigger in the current outbreak [4]. The first Ebola virus species was discovered in 1976 near the Ebola River, in the Democratic Republic of Congo [2]. Currently the largest Ebola virus disease outbreak is ravaging West Africa [5]. It first occurred in Guinea, and then spread to Liberia, Sierra Leone, Nigeria, Senegal, Mali, and the United States [6,7]. On August 8, 2014, the World Health Organization announced the current outbreak as a Public Health Emergency of International Concern (PHEIC) [8].

\section{Emergence of the Ebola Zaire Strain}

African fruit bats are the presumed natural reservoir host species of the often fatal Ebola virus [9]. The Ebola virus is potentially fatal once transmitted to humans and other animals, yet does not cause fatality in bats [9]. Researchers believe that the virus emerged via contact of humans and nonhuman primates with infected bat fecal matter, leftover fruit, and body fluids, with transmission perpetuating through direct contact [9].

The key to understanding how to treat Ebola may lie in observing how the Ebola virus replicates [9]. Studies of bat genomes suggest that their resistance to viruses is imparted by different genes playing a role in the early immune response to the virus [9]. Bat genes responsible for the immune response are evolving at a much faster pace when compared to other species, suggesting that bat genes co-evolve with virus genes [9]. Parts of the bat immune system remain turned on, whereas the immune response must be activated in humans and nonhuman primates, this difference allows bats to actively respond to a virus [9]. Studies are needed to determine whether 
redirection of the human and nonhuman primates immune system could lead to a reduction in Ebola's death rate [9]. Bats play a vital role in the ecosystem, controlling insects and plant pollination, eradicating these mammals- a commonly sought out solution, is not the a viable means for resolution of the Ebola outbreak [9]. Rather we should focus our energy on understanding why and how bats have evolved to resist fatality in the face of the Ebola virus [9].

Morphological analysis of the Ebola virus has shown that it is identical to the Marburg virus [10]. The structural similarity between the viruses is the underlying reason for the shared symptom profile presented by those infected with Ebola, often misdiagnosed with malaria, typhoid, Lassa fever, yellow fever, or influenza [4]. This morphological advantage provides Ebola with ample time to exist in infected individuals, increasing its timeframe to make contact, enhancing its spread amongst unsuspecting family members and healthcare workers, and ultimately creating chains of transmissions [4]. There is some evidence suggesting that the virus strain in the current epidemic is showing signs of genetic mutations [11]. The current Ebola Zaire virus strain is a $19.0 \mathrm{~kb}$ nonsegmented, single stranded, negative sense, RNA genome which encodes seven genes which produce eight proteins, and last caused an epidemic in 2008 [10,12,13]. Sequencing of 99 Ebola viral genomes from the current outbreak in Sierra Leone display inter- and intra-host variations, which are related to the current transmission dynamics [14]. A prominent intrahost variation is the RNA editing site of the glycoprotein gene, which has been found in those infected [14].

Researchers often wonder if Ebola Zaire existed in the African landscape prior to 1976 or evaded detection and documentation [15]. This question still remains unanswered, yet several associations have been made with the specific viral strain [15]. Studies of Ebola Zaire suggest that all emergences between 1976 and 2005 are descendants of the Yambuku like virus, rejecting the idea that the strains are evolving independently [15]. Further evidence suggests that the descendents spread through outbreak regions [15]. New Ebola Zaire cases studied in Central Africa were found to spread to specific geographic distances from their previous cases, spreading at a rate of $50 \mathrm{~km}$ per year [15]. With increased geographical spread, increased genetic divergence was found among the viral genotypes [15]. Studies analyzing previous outbreaks of Ebola Zaire suggest that it employs a mechanism of spread [15].

The current West African Ebola virus variant of Ebola Zaire is a likely divergent from Central African lineages from around 2004 [14]. This is evidenced by a mapping to the strain from the oldest outbreak, suggesting a substitution rate of $8 \times 10^{-4}$ per site, per year [14]. This suggests that outbreaks are indeed representative of independent zoonotic transmissions, yet are derived from a genetically diverse natural reservoir [14]. The current 2014 outbreak displays a substitution rate approximately two times the rate observed between outbreaks [14]. The virus is successful in efficiently deteriorating the host's immune system by first suppressing the innate immune system and later disarming the adaptive immune system [16].

\section{Evading the Host's Immune Response}

In humans, the Ebola virus rather than initially attacking the immune system manifests by activating the immune system [9]. During the early phase, Ebola diminishes the host's immune response against the virus, and allows for increased viral replication and reduces antibody production [9]. Once the virus has taken over, the immune system activates and results in an exaggerated immune response [9]. The highlight of an Ebola infection is the over stimulation of the immune system which results in more harm than benefit to the infected individual, destroying vital organ function [9].

The Ebola genome consist of a nucleoprotein, viral proteins, VP35, VP40, VP30, VP24, with glycoproteins GP1 (sGP, ssGP) and GP2, and an RNA-dependent RNA polymerase L [12,13]. Genome replication and transcription of viral genes require the nucleoprotein to encapsulate the genome and complex with VP30, VP35, and viral RNA-dependent RNA polymerase L [13]. During replication, the nucleoplasmid forms helical structures interacting with VP35 and VP24 to produce the nucleocapsid structures [12]. The viral proteins interact with type I interferon's (IFN), contributing to the increased virulence of the Ebola virus, in turn suppressing the host's innate immunity $[13,16]$. VP24, functions in the nucleus to prevent STAT1 localization, resulting in a direct signaling blockade of IFN- $\alpha / \beta / \gamma$ [13]. Studies suggest that VP24 is critical in contributing to the virulence and seems to play a role in host adaptation [12]. VP35 blocks type I IFN induction independently by directly binding to dsRNA and competing with RIG-I-like receptor binding, inducing sumoylation of IRF7, decreasing its transcriptional activity, and antagonizes PKR activity [13]. VP35 along with RNA-dependent viral polymerase L, are involved with replication, transcription, and processing, including polyadenylation and capping [12]. Viral budding through host cells is determinant upon VP40, a matrix protein [13]. VP24 also a minor matrix protein is involved in the formation of the nucleocapsid, along with regulation of viral transcription and replication [12]. Strong virulence has been associated with inhibition of type I interferon [13].

The type I transmembrane glycoprotein is the only surface protein exhibited by Filoviruses [12]. The glycoprotein's are involved in mediating attachment, entry, and fusion with host cells [12]. Cellular protease furin processes GP1 and GP2 to produce the soluble sGP and ssGP [13]. sGP is a nonstructural, soluble glycoprotein, unique in that it is translated from non-edited mRNA species, and is secreted from infected cells [12]. There is a possibility that sGP serves to function as a protective antiinflammatory molecule, via protecting the endothelial cell barrier [12].

Cells of the mononuclear phagocyte system are the first cells to be manipulated by the virus and are responsible for providing the host with innate and adaptive immunity (Figure 1) [12]. Initial target cells include monocytes, macrophages, and dendritic cells, which are responsible for quickly spreading the virus to various host organ systems [12]. Studies in nonhuman primates have detected infected Kupffer cells in the liver within two to three days of infection with Ebola virus, demonstrating the rapid rate of replication and spread of the virus [12]. Main target organs of the Ebola virus include the liver and adrenals, evidenced by viral replication in parenchyma cells, which 
are infected one to two days following macrophage infections [12]. Secondary target cells are the fibroblasts and endothelial cells, which non-human primate studies have shown to be affected after five to seven days of infection [12]. Filovirus infection uses blood as a means to spread throughout the body, by utilizing the power of free virions and those housed inside infected monocytes [12]. The infection is further disseminated by monocytes reaching connective tissue, infecting fibroblasts, which carry the viral progeny to distant body systems [12]. It is important to note that no inflammatory cellular response activity has been observed at the site of viral replication with fatal Filovirus [12]. Infected tissue cells have not been found to be surrounded by monocytes, lymphocytes, or neutrophils, a highlight mechanism of fatal Filoviruses [12].

Entry can be gained into susceptible cells via lipid-raftdependent mechanisms, receptor-mediated endocytosis, or macropinocytosis, with receptor binding and attachment mediated by glycoprotein 1 (Figure 1) [12]. Various receptors have been implicated in viral entry including the folate receptor, glycan-binding proteins of the C-type lectin family, B1-integrins, T-cell immunoglobulin and mucin domain 1 (TIM-1), Tyro3/Axl/Mer receptor family (TAM) [12]. There is no evidence for a "primary" receptor responsible for allowing viral entry into the cell [12]. Utilizing one of these entry pathways, the virus makes its way into endosomes where its fusion takes place, initiated by GP1 which must be cleaved by proteases cathepsin B and cathepsin L, and mediated by GP2 [12].

Post-fusion, the virus gains access to the host's replication machinery and provides its nucleocapsid as a template for transcription and replication [12]. Transcription of the seven genes allows for the production of the monocistrionic mRNAs, which undergo processing with capping, and polyadenylation [12]. Replication produces copies the viral RNA into "full-length positivesense replicative intermediates" and RNA antigenomes encapsulated by nucleoplasmid proteins are key for production of more virus copies [12]. The nucleoplasmid controls the production of nucleocapsid like structures via interaction with viral proteins, occurring in the cytoplasm. This is evidenced by granular material observed in the cytoplasm of cells nine hours after infection with Ebola Zaire via electron microscopy [12]. Post-replication and assembly the nucleocapsids are transported for virus budding to the intracellular membranes, multivesicular bodies, or the plasma membrane [12]. The transport to these sites is mediated by both the nucleoplasmid and VP40 [12]. Furthermore, the Ebola virus has been shown to interact with the hosts COP II system and ESCRT machinery facilitating its exit [12]. Currently, two models explore possible budding mechanisms for the virus these include horizontal budding or vertical budding [12].

The virus' strength in production capacity relies in delaying the death of an infected host cell, during the early course of an infection [12]. Various mechanisms of cell death may be employed once the virus has exhausted the infected cells replication machinery including apoptosis, autophagy, and necrosis (Figure 1) [12]. Apoptosis has been witnessed in tissue lymphocytes of infected nonhuman primates [12]. Lymphocytes also undergo apoptosis, though they are not involved in Filovirus replication, and do not become infected, possibly due to a lack of receptor for the virus [12]. Lymphocyte depletion, occurring in both humans and non-humans is fundamental to Filovirus infection and can be seen in both the blood and tissues of the host [12]. Apoptosis of non-infected lymphocytes results in depletion of CD4T cells, CD8 T cells, and NK cells [12]. Lymphocyte apoptosis though valuable is not unique to only Filovirus, the activity has also been observed in human immunodeficiency virus, human herpesvirus 6, and vaccinia virus [12].

Other cells, which do not undergo apoptosis, evidenced by infected animal tissue analysis, include macrophages, dendritic cells, hepatocytes, and endothelial cells, which have been shown to either look normal or necrotic [12]. During an Ebola infection, it has been noted that the amount of necrotic cells increases [12]. Though the number of dendritic cells was found to decrease in the early phase of infection in some non-human primates, and levels were undetectable six to seven days post infection in others [12]. The variability in dendritic cell concentrations amongst non-human primates indicates that there may be species-specific variability in the expression of the Filovirus infection [12].

Studies have shown that those with lower levels of 'pro-inflammatory cytokines, T-cell survival, production of anti-filovirus antibodies, and lower viremia' early in the course of infection have better chances of survival [12,13]. Survival of the host has been shown to be correlated with a reduction in viral load, with studies showing a 2-3 log difference in viral titers between survivors and the deceased [13].

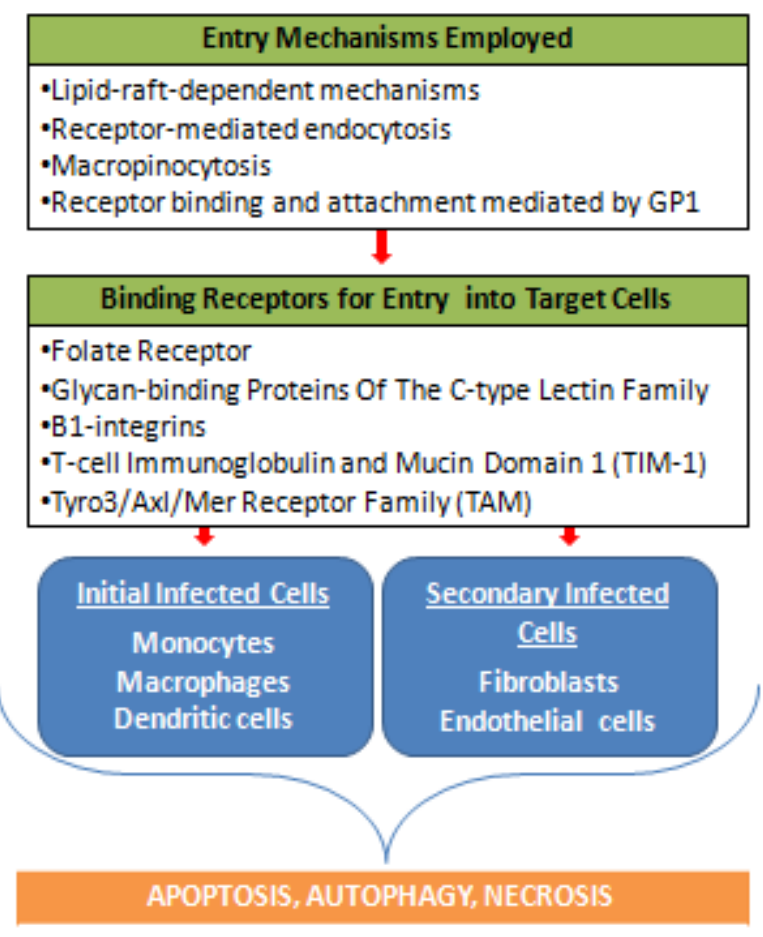

Figure 1. Ebola Evades the Immune System

EVD employs various mechanisms to gain entry into the cell, by binding to receptors on target cells [12]. Current studies have not yet determined if EVD utilizes a "primary receptor" to bind to target cells [12]. Postbinding, monocytes, macrophages and dendritic cells are the first to be infected, followed by fibroblasts and endothelial cells [12]. The cells then either undergo apoptosis, autophagy, or necrosis [12]. 


\subsection{Chronicled Epidemiology of the Ebola Virus}

Of the various strains, Ebola Zaire has a higher virulence with a case fatality rate (CFR) of 61-89\%, and only requires 10 aerosolized particles to cause an infection in humans $[18,19]$. It is important to note that infected individuals have not been found to present with any predisposing factors to the infection [10]. Adults ages 2030 are more prone to contracting the Ebola Virus [10]. During the current outbreak, patient ages range from 15 to 44 years, which represent $44 \%$ of the population and $49.9 \%$ of those infected are male [20]. Age greater than 45 years is a significant risk factor for death when compared to being less than 44 years of age (odds ratio, 2.47; 95\%CI, 1.79 to 3.46) [20]. Examining gender demographics of the current epidemic show no significant differences in prevalence between the sexes across countries [20]. Of individuals exposed to Ebola via close contact, $45.8 \%$ asymptomatic individuals have been found to develop both immunoglobulin $M$ and immunoglobulin $G$ in response to Ebola antigens [18]. A single infected case of Ebola is self-limiting $60 \%$ of the time, whereas an initial appearance of five cases results in a major epidemic $90 \%$ of the time [18]. Analysis of previous outbreaks suggests higher virulence levels in the initial cases rather than the successive waves of the infection [19]. The cause for the increased initial virulence and subsequent increased chance of survival has yet to be determined [19].

The incubation period is 2-21 days [19], during which Ebola is less likely to be transmitted [21]. Using data from previous outbreaks, the mean latent period has been estimated to be 9.4 days [18]. Previous outbreaks have also derived the mean infectious period to be 5.7 days [18]. Death of an infected individual usually occurs after an average of 10 days, from the onset of hemorrhagic complications, in 50-90\% of infections [21]. Secondary transmissions may be a result of contact with the deceased, extending the infectious period from time of death, instead to time of burial [18]. The mean generation time of the virus in previous outbreaks is 12 days (standard deviation 12 days) [18]. The end of an outbreak is marked when no new cases emerge for 42 days; this is twice the incubation period [19]. The first outbreak occurred in 1976, with the most recent and largest to date outbreak occurring presently in 2014 [22]. The mean years between outbreaks has been found to be 1.49 (1.02-2.24) [22]. A recent estimate suggests that currently 22 million Central and West Africans are at risk of an Ebola infection [18].

Table 1. Historic Trends for Ebola Zaire Strain

$\begin{array}{cc}\text { Ebola Zaire Case Fatality Rate (CFR) Range } & 61-89 \% \text { [18] } \\ \text { Mean Mortality Rate } & 85-95 \% \text { [19] } \\ \text { Incubation Period } & 2-21 \text { Days [19] } \\ \text { Mean Infectious Period } & 5.7 \text { Days [18] } \\ \text { Mean Latent Period } & 9.4 \text { Days [18] } \\ \text { Mean Generation Time } & 12 \text { Days [18] } \\ \text { Mean Years between outbreaks } & 1.49 \text { years [22] }\end{array}$

Mortality rate is defined as the number of total deaths across all waves of the outbreak period [19]. Ebola Zaire has historically exhibited a mortality rate of $85-95 \%$ (Table 1) [19]. Previous outbreaks relate a higher mortality rate with those found closest to the original exposure source [19]. Previous notions suggested that strain virulence was solely a product of viral genetics, whereas current trends suggest that the socio-political and environmental climate are key variables in creating the flux in mortality rates and spread of infection [19].

Table 1. Historic Trends for Ebola Zaire Strain Estimated epidemiological trends for Ebola Zaire strain, reflective of previous outbreak patterns. Table summary has been adapted from Chowell and Nishiura's transmission dynamics and control of EVD review found in Biomedcentral 2014 [18,19,22].

The case fatality ratio (CFR) confers the virulence of the pathogen by calculating the proportion of number of deaths to total number of Ebola cases [18]. When interpreting current CFR estimates, it is important to note that the values may reflect incomplete information regarding identified and unidentified cases [20]. The case fatality rate differs depending on the outbreak, region, and virus strain [23], previous outbreaks have had case fatality ratios as high as $90 \%$, ranging from 41 to $89 \%$ [18,22]. The CFR, specific to West Africa has been estimated to be 70.8\% (95\% CI: 68.6 to 72.8) [18]. The CFR for Nigeria was calculated to be $45.5 \%$ based on data from the 11 identified cases [20]. The CFR of hospitalized cases was $64.3 \%$ (95\%CI, 61.5 to 67.0) across the West African region [20].

\section{Transmission Dynamics}

Ebola is introduced into the human population through close contact with blood, secretions, organs or other bodily fluids of infected animals [24]. Ebola then spreads in the community through human-to-human transmission via direct contact, defined as contact between broken skin or mucous membranes such as lips, nostrils, mouth, eyes or genitals; with blood or bodily fluids from an infected person (Figure 2) [2]. Ebola is also transmitted by indirect contact with objects contaminated by the virus, particularly needles and syringes [2]. Burial ceremonies in which mourners have direct contact with the body of the deceased person can also play a role in the transmission of Ebola (Figure 2) [25]. Aerosol dissemination of Ebola virus has not been established as a mode of transmission in humans [26]. In vitro testing has established airborne transmission of the virus in primates [10]. Infected patients typically do not become contagious until they develop symptoms; therefore, the potential for widespread EVD infection is considered low, since the disease is only spread by direct contact with the secretions from someone who is showing signs of infection [27].

Often hunters get infected at the time of slaughter, handling or transport of primates or other infected animals collected in the forest (Figure 2) [28]. These hunters, in turn, infect their family and friends usually while caring for the sick and during burial processes [28]. Traditional healers have also played a direct role in the amplification of the epidemic (Figure 2) [28]. Traditional healers usually treat by making direct contact (e.g. using their hands) with the sick, which presents an opportunity for transmission (Figure 2) [28]. They also keep infected individuals in their home for several days, in contact with members of their families, which further spread their disease in the community [28]. Epidemics in rural settings are usually of smaller magnitude, yet become problematic when spread to other community levels such as health care systems [29]. 
Healthcare workers in close contact with Ebola patients are at the highest risk of getting sick [30]. To date, more than 240 healthcare workers have developed the disease in Guinea, Liberia, Nigeria, and Sierra Leone, and more than 120 have died, depriving these countries, not only of experienced and dedicated medical care but also of inspiring national heroes (Figure 2) [30]. Several factors help explain the high proportion of infected medical staff. Exposure to Ebola virus can occur in healthcare a setting where hospital staff is either not adequately equipped with supplies or not wearing personal protective equipment properly, such as masks, gown, or gloves [25].

Short supply of personal protective equipment and sterile injection needles is the norm in many hospitals in sub-Saharan Africa [31]. Hospital acquired transmission has occurred because contaminated injection equipment wasn't sterilized between uses. Without adequate sterilization of the instruments, virus transmission can continue and amplify the outbreak [25]. In addition, the heavy toll on health care workers further impedes control efforts. WHO estimates that, in the three hardest-hit countries, only one to two doctors are available to treat 100,000 people, and these doctors are heavily concentrated in urban areas. This can lead to the closing of health facilities, especially when staff refuses to come to work, fearing for their lives [30].

\subsection{Epidemiological Implications of Transmission}

Transmission route analysis of the 1976 Ebola Zaire outbreak showed 57 cases infected via injection and 109 cases due to person-to-person contact during a 21 day range [4]. Transmission dynamics of the 2014 outbreak dynamics support this phenomenon demonstrating a higher probability of transmission between close contacts and a lower probability with casual contact [32]. A previous study highlights that the serial interval for household members, defined as the time of disease onset in the initial case to disease onset in the secondary case has ranged from 7 to 17 days [18]. Close contact is also made with bodies of the infected deceased during traditional funeral practices, accounting for $60 \%$ of the Ebola infections witnessed in Guinea [23]. Proper handling of the deceased would decrease the transmission coefficient by $75 \%$ for burial practices [21].

Community size is directly related to the extent of transmission; an increasing community mixing size increases the probability of infecting an individual resulting in an epidemic [32]. Community size is a variable in Ebola transmission dynamics and plays a role when those infected shift from households to hospital settings [32]. Hospital infrastructure in West Africa exhibits a low ratio of healthcare workers to the population along with a lack of adequate personal protective equipment [18]. The hospital setting may amplify transmission via health care workers, but serves to limit transmission within the community by isolating the patient. The transmission rate is a fixed constant, but the population of susceptible contacts fluctuates based on the setting [32]. Analysis of previous outbreaks has demonstrated that an increasing hospitalization rate reduces the predicted epidemic size [21]. Implementation would involve rapid identification, hospitalization, and isolation of infected individuals, thereby decreasing the transmission coefficient by at least 50\% [21]. Independent of the community size are good hygiene practices including frequent hand washing and chlorine stations which reduce the transmission rate. Limited community mixing sizes provide an explanation for the previous outbreaks with smaller distributions and limited chains of transmission [32].

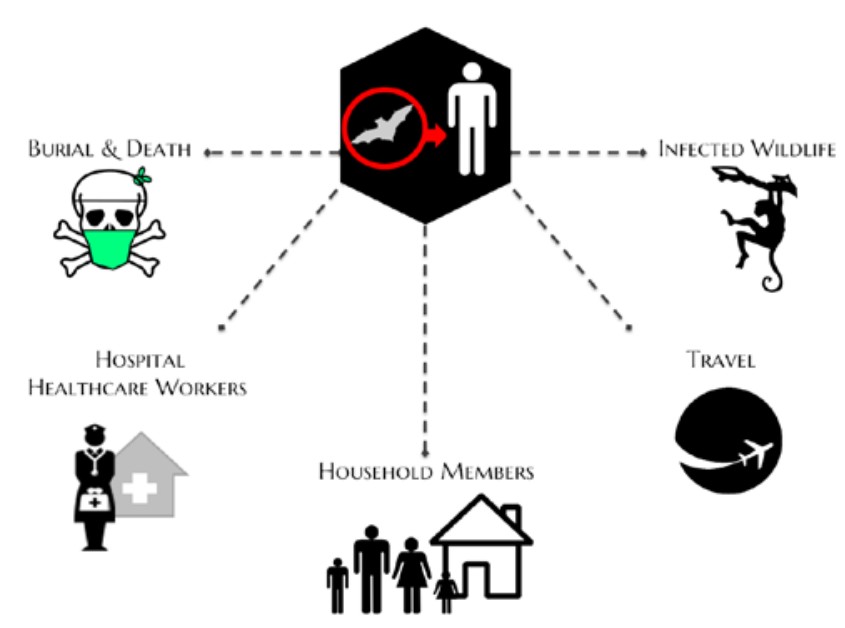

Figure 2. Transmission of EVD

Transmission of EVD permeates through society via direct contact between an EVD infected individual and an exposed individual. Contact events have been associated with burial proceedings of the EVD infected, within hospitals, among tribal healers, between family members, during travel, and with infected wildlife [2,25,28,33-40]

\section{Current West African Epidemic}

The first West African EVD outbreak began in December 2013, in Guinea but was not detected until March 2014, after which it spread to Liberia, Sierra Leone, Nigeria, Senegal, Spain and the United States [41,42]. Researchers believe that the first human case leading to the 2014 outbreak was a 2 year old boy who died on December 6, 2013 just a few days after falling ill in the village of Meliandu in Guéckédou, Southeastern Guinea [43]. From Meliandou, the disease appears to have transmitted to Macenta by early February 2014, and to Kissidougou by late February 2014. The first death attributed to EVD occurred on March 17, 2014 in the capital city of Conkary, of a businessman who was ill only for one day, and had travelled from Dabola in central Guinea [44]. His four siblings all tested EVD positive, and since then the disease has spread to neighboring countries [44]. In Liberia, an EVD infected woman arriving from Guinea transmitted the disease to her sister in Foya, a town close to Guinean border [44]. The sister travelled to the Liberian capital Monrovia, then to Frestone Rubber Plantation Camp, northeast of the city, before dying on April 2, 2014 [44]. The first person reported infected in the spread to Sierra Leone was a tribal healer, who had treated one or more infected people and died on May 26, 2014. According to tribal tradition, her body was washed for burial and this appears to have led to infections in women from neighboring towns [45]. 
Mali is currently facing its second EVD outbreak, even after making strides with contact tracing and containing the first outbreak, which was traced to a two year old Guinean girl who lost her battle to EVD, passing on October 24, 2014 [46]. As of November 12, 2014, four cases of EVD have been confirmed, and four have died [6]. Tracing of the second outbreak suggests that it was initiated by an ill imam travelling from Guinea, to Mali in an attempt to receive better care at the Pasteur Clinic in Bamako [47]. The imam was not suspected to have EVD since clinicians believed he only presented with kidney failure, and only became aware once members of their team and the imam's family showed signs of EVD [47]. The imam passed away on October 27, 2014, and his body was sent back to Guinea for burial [47]. Factors complicating contact tracing in the imam's case are mainly related to his revered status as a community leader, allowing his deceased body to be washed at a larger mosque, and prepared for burial at a smaller mosque, and the fact that he showed symptoms starting October 17, 2014, which were detected on November 10, 2014 [47]. All suspected cases in relation to the imam's case are now in quarantine, and all mosques and clinics travelled to by the imam have been shut down [47].

On September 30, 2014, the CDC declared the first case of EVD in the United States [48]. EVD infected Thomas Eric Duncan, traveled from Liberia to Texas, and was later hospitalized with diagnosed Ebola symptoms at Texas Health Presbyterian Hospital in Dallas [48]. Upon arrival to the U.S. he was seen at the hospital, and despite telling a nurse that he had arrived in the US from West Africa, he was sent home with antibiotics [49]. He returned to the hospital by ambulance on September 28,2014 and was placed in isolation [50]. On October 8, 2014 T.E. Duncan died of Ebola virus disease [51]. On October 12, 2014 Nina Pham, a healthcare worker who had treated Duncan tested positive for Ebola Disease [52]. She was immediately transferred to the National Institutes of Health (NIH) in Bethesda, Maryland on October 16,2014 [53]. On October 14, 2014, the CDC confirmed a second health care worker, who also treated T.E. Duncan, Amber Joy Vinson, tested positive for Ebola [54]. Vinson was transferred to Emory University Hospital to receive treatment [53]. In the United States, there have been four confirmed cases and one death [41]. On October 23, 2014, Craig Spencer, a doctor who recently returned from West Africa, was the fourth case of Ebola diagnosed in the U.S, and is among the nine cases who have been treated in the United States [55,56]. Of the nine treated, only one did not survive, marking survivor Dr. Spencer as the last Ebola case diagnosed in the United States as of November 11, 2014 [55]. The soon to be tenth case of an infected EVD patient, is Dr. Martin Salia, who is being flown from Sierra Leone to be treated in Omaha, Nebraska starting on November 15, 2014 [57]. Symptomatic on November 6, 2014 Dr. Salia underwent Ebola testing and resulted negative, when tested again on November 10,2014 he tested positive [57]. Dr. Salia's contact with EVD infected patients through his line of work as a surgeon remains undetermined [57].

As of November 12, 2014, 14,098 (probable, confirmed and suspected) cases and 5,160 deaths have been reported in the current outbreak of Ebola virus disease by the ministries of Health of Guinea, Liberia and Sierra Leone
[6]. In Nigeria, there have been 20 cases and a total of 8 deaths [41]. In Senegal, one case had been confirmed, with no further Ebola deaths or further suspected cases [41]. The World Health Organization declared the end of the Ebola outbreak in Senegal on October 17, 2014 and Nigeria on October 19, 2014, with no new emerging cases for 42 days [58]. Many experts believe that the official numbers of reported cases, underestimate the size of the outbreak because of families' widespread reluctance to report cases [59].

\subsection{Epidemiology of the Current Outbreak}

Analysis of the growth dynamics of the 2013-2014 epidemic suggests variations in trends and final outbreak size between Sierra Leone, Guinea, and Liberia, which share common cultural and geographical traits (Table 2) [22,32]. The rate of transmission, defined by the average number of those infected by each person R0 within a naive population, is equal across all three countries [32]. Variability in R0 estimates is due to variations in models and accepted assumptions [18]. The basic reproductive number is the average number of secondary infections generated by one primary case in an entirely susceptible population [23]. Previous outbreaks (1995, 2000) produced a basic reproductive number of 2.7, with a range of 1.34-3.65 [23]. The current outbreak has a basic reproduction number ranging from 1.5 to 2.5 [18]. If epidemiologic controls are set to reduce transmissions in hospitals and during burial practices then the effective reproduction number could be decreased to 0.3-0.4 [23].

A variable effecting containment of the West African epidemic is time [58]. It has been predicted that containment can be achieved if infected cases are reported and isolated within three days on average, between the appearance of symptoms and isolation [58]. Delaying the identification of an infected case is a variable in predicting the severity of an Ebola outbreak [18]. A delay of five days does not result in an outbreak, yet an infected case remaining unidentified for over two weeks is likely to result in an Ebola outbreak [18]. Mean time of symptom onset to hospitalization, a function of infection was $5.0+4.7$ days, with a maximum of greater than 40 days, for both community members and health care workers, which can be reduced with early identification strategies [20]. The mean duration of a hospital stay was found to be 6.4 days, the cause for which more hospital beds are needed [20]. Once admitted, the mean time to death was $4.2+6.4$ days, and mean time to discharge 11.8+6.1 days [20]. Unfortunately, being labeled as an infected EVD case elicits stigma from a community [18]. Uninformed household members do not disclose infection status of a loved one to members of the community to prevent avoidance [18]. Stigmatized notions prevail due to the high CFR of Ebola allowing communities to associate isolation of an individual directly to subsequent death [18]. Lack of knowledge of Ebola in West Africa has created dichotomous communities, comprising of those either ignoring its existence, or attributing its prevalence to witchcraft or political conspiracy theories [18]. Aiding the spread of the virus is fear, some fear the hospital and stay away as a means of protecting themselves from being infected, and those who are infected hide, going unreported, in order to prevent facing stigma [11]. 
Conspiracists feel that the epidemic has been fabricated by governments to manipulate their people or garner financial resources from developing nations [18].

Table 2. Trends for Current West African Ebola Zaire Strain \begin{tabular}{cc}
\hline West African 2014 Ebola Zaire CFR & $70.8 \%$ (95\% CI: 68.6 - 72.8) [18] \\
Basic Reproduction Number & R0=1.5 - 2.5 [18] \\
Hospitalized Cases CFR & $64.3 \%(95 \%$ CI, 61.5 - 67.0) [20] \\
Mean Duration Of A Hospital Stay & 6.4 days [20] \\
Mean Time To Death & $4.2+6.4$ days [20] \\
Mean Time To Discharge & $11.8+6.1$ days [20]
\end{tabular}

Table 2. Epidemiological estimates specific to the Ebola Zaire strain of the 2013-2014 West African EVD outbreak. The table highlights key time periods extracted from the New England Journal of Medicine's, Ebola Virus Disease in West Africa - The First 9 Months of the Epidemic and Forward Projections, compiled by the WHO response team $[18,20]$.

Mobility data demonstrates that in the short-term, the risk of international spread of the epidemic is low, yet spread within African countries is more probable [18]. In the global community, fear is a response to the unknown, and may be mitigated by performing transparent risk communication and making concerted efforts to understand the mechanisms of Ebola virus disease [23]. Further comparisons between West Africa and the developing nations show that an outbreak is unlikely in developing nations, which have strong foundations for infection control [18]. Analysis of data has demonstrated a relationship between changes in climate, specifically transitioning from dry to wet, with Ebola outbreaks [18]. Analysis of outbreaks from 1976-2014 has shown lower temperatures and higher absolute humidity to be related to the onset of an Ebola outbreak [18].

\subsection{Guinea}

The current epidemic originated in Guinea and spread throughout the West African region. Growth in Guinea appears to follow a linear pattern, and is occurring subexponentially [32]. The effective reproductive number increased over time, specifically in mid-August when the outbreak made its way to the populous city of Conakry (Table 3) [32]. The basic reproduction number has been found to be $\mathrm{R} 0=1.11$ (as of September 23, 2014) [58]. As of September 23, 2014 (Day 182) the ratio of exposed cases to infectious is $\mathrm{E}(182) / \mathrm{I}(182 \approx 2.56$ [58]. The ratio of improperly handled deceased cases to infectious cases is $\mathrm{C}(182) / \mathrm{I}(182) \approx 0.66$ [58]. The ratio of cumulative reported cases to cumulative unreported cases has been found to be approximately 4.95 [58]. The CFR of health care workers was found to be $56.1 \%$ (95\% CI, 41.0 to 70.1 ) [20]. As of September 14, 2014 the doubling time of the epidemic in Guinea was 15.7 days [20].

\subsection{Liberia}

The epidemic is expanding at a faster rate in Liberia than in Guinea, even though the epidemic originated in Guinea [32]. Growth in Liberia appears to be exponential, with approximately 10 cases per day in July, 40 cases per day in August and 70 cases per day in September [32]. One model attributes funeral transmissions as a factor in the rapid exponential growth in Liberia [32]. The simple increase in the amount of those infected, correlates with a decrease in implementation of effective means to limit transmission [32]. Liberia also has a community mixing size five times greater than Guinea, creating an increased threshold number of interactions blurring the boundaries of a community [32]. Furthermore, community mixing sizes can be positively or negatively influenced by various epidemic controls [32]. A second model predicts that the exponential growth seen during the early period of the outbreak may be attributable to a superposition of several outbreaks staggered in time, attributing to the wave like nature of the infection observed during previous outbreaks [32].

The effective reproductive number increased earlier, mid-July in Liberia, when the outbreak spread to Monrovia (Table 3) [32]. The basic reproduction number has been found to be R0=1.54 (as of September 23,2014) [58]. As of September 23, 2014 (Day 98) the ratio of exposed cases to infectious is $\mathrm{E}(98) / \mathrm{I}(98) \approx 3.35$ [58]. The ratio of improperly handled deceased cases to infectious cases is $\mathrm{C}(98) / \mathrm{I}(98) \approx 0.58$ [58]. The ratio of cumulative reported cases to cumulative unreported cases has been found to be approximately 1.37 [58]. The CFR of health care workers in Liberia was found to be $80.0 \%$ (95\% CI, 68.7to 87.9) [20]. As of September 14, 2014 the doubling time of the epidemic in Liberia was 23.6 days [20]. Liberia has also reported higher deaths (58\%) in suspected Ebola cases, when compared to Guinea or Sierra Leone [20]. One explanation being, that these suspect cases may have departed prior to receiving a diagnosis [20].

\subsection{Sierra Leone}

Growth dynamics of Sierra Leone are in between those of Guinea and Liberia (Table 3) [32]. Individuals from Sierra Leone have been previously exposed to the Ebola virus, yet they have not been involved in epidemics till now [18]. The basic reproduction number has been found to be $\mathrm{R} 0=1.26$ (as of September 23, 2014) [58]. As of September 23, 2014 (Day 119) the ratio of exposed cases to infectious is $\mathrm{E}(119) / \mathrm{I}(119) \approx 2.49$ [58]. The ratio of improperly handled deceased cases to infectious cases is $\mathrm{C}(119) / \mathrm{I}(119) \approx 0.57$ [58]. The ratio of cumulative reported cases to cumulative unreported cases has been found to be approximately 1.78 [58]. The growth rate is biphasic in Sierra Leone, the early phase displaying higher growth, possibly attributable to group cases found in hospitals [18]. As of September 14, 2014 the doubling time of the epidemic in Sierra Leone was 30.2 days [20].

Table 3.Trends for Current West African Ebola Zaire Strain per Country of Outbreak

\begin{tabular}{|c|c|c|c|}
\hline & Guinea & Liberia & Sierra Leone \\
\hline Day of Outbreak & Day $182[58]$ & Day $98[58]$ & Day $119[58]$ \\
\hline Basic Reproduction Number & $\mathrm{R}_{0}=1.11[58]$ & $\mathrm{R}_{0}=1.54[58]$ & $\mathrm{R}_{0}=1.26[58]$ \\
\hline Ratio Of Exposed To Infectious Cases & $\approx 2.56[58]$ & $\approx 3.35[58]$ & $2.49[58]$ \\
\hline Ratio Of Improperly Handled Deceased to Infectious Cases & $\approx 0.66[58]$ & $\approx 0.58[58]$ & $\approx 0.57[58]$ \\
\hline Ratio Of Cumulative Reported to Cumulative Unreported Cases & $4.95[58]$ & $1.37[58]$ & $1.78[58]$ \\
\hline Doubling Time Of The Epidemic & 15.7 days[20] & 23.6 days [20] & 30.2 days $[20]$ \\
\hline
\end{tabular}


Table 3: Estimated epidemiological trends per major outbreak countries Guinea, Liberia and Sierra Leone. The day of outbreak, basic reproduction number, ratio of exposed to infected, ratio of improperly handled deceased to infectious cases, ratio of cumulative reported cases to cumulative unreported cases are all statistical estimates reflective of the West African Ebola virus epidemic as of September 23, 2014 [58]. The calculated doubling time, in the specified regions of the epidemic, is reflective of the West African Ebola virus epidemic as of September 14,2014 [20].

\section{Exploring Possible Outbreak Triggers}

Studies analyzing underlying patterns between outbreaks hint towards a possible association between various environmental factors and the emergence of Ebola outbreaks in humans [60].

\subsection{Temperature}

An analysis of outbreaks from 1976 to 2014 correlate observed lower temperatures with Ebola outbreaks (Figure 3) [60]. Related to the current 2014 outbreak, it has been found that the mean temperature found in Guinea is similar to mean temperatures recorded in previous regions infected with Ebola Zaire [60]. Within human hosts, lower temperatures have been associated with changes in the immune response [60].

\subsection{Humidity}

Along with temperature, higher absolute humidity has also been found to be a possible trigger of an Ebola outbreak (Figure 3) [60]. Though this pattern has been observed, it was not directly observed in Guinea in 2014, where the mean absolute humidity was found to be lower than other regions with previous outbreaks [60]. Lower temperatures and higher humidity together, are loglinearly associated with an increased risk of EVD outbreaks in humans [60].

\subsection{Seasonal Shift}

Analyses of previous outbreaks are starting to trace possible underlying cyclical and seasonal patterns contributing to Ebola outbreaks. Consistency was found when comparing seasonal temperature variation across the following five countries, Democratic Republic of the Congo, Gabon, Guinea, South Sudan, and Uganda [60]. Months, June through August were found to be cooler, and February through April warmer than the mean temperature [60]. Outbreaks have occurred in both dry and wet seasons [60]. Further observations have concluded that outbreaks emerge during the shift from rainy to dry seasons, with dry seasons marking the outbreak event [61].

Currently, it is postulated that bats are the natural reservoir of Ebola, and they appear to have behavioral associations with seasons [60]. Wet climate, or the rainy season appears to be the season of choice for bats to mate and engage in fighting rituals [60]. This is further supported by the analysis that pregnant female and adult bats have highest seropositivity levels for Ebola [60]. The rainy season is also the time when insect biomass is 3.9 times higher in Makokou, Gabon [62]. The rainy season also sparks fruiting, ensuing foraging and competition between animals allowing hosts to come into contact with the reservoir [62]. Furthermore, seasonal migration patterns of bats may contribute to the cyclical nature of their contact with humans and resulting EVD outbreaks (Figure 3) [60]. A possible trigger in the 2014 outbreak could be the shift in the seasonal migratory route of bats [60].

\subsection{Deforestation}

The forest has played a central role in every Ebola outbreak being either a gallery or continuous tropical forest [62]. Contributing to steeper climate change is the progressive deforestation, as exemplified by Guinea [61]. Guinean's have recently observed a very dry and abnormally long dry season which is a possible result of decades of deforestation [61]. Furthermore, Guinea exhibits a declining socio-economic infrastructure attributable to a corrupt government and a lack of resources, being the 178 poorest countries out of 187 ranked by the United Nations Development Programme Human Development Index [61]. Pocketed communities residing in Guinea's forest were uprooted by clear-cut logging, further degrading Guinea's forest infrastructure in an attempt to bolster the economic infrastructure (Figure 3) [61]. Poverty, the initial driving force, compelled communities to plunge deep into the forest to hunt game, gather wood for charcoal, and extract minerals subsequently deteriorating the forest structure [61]. Deforestation not only created an opportune environment via habitat disruption, to increase contact frequency between bats and humans, but it also created the porous borders which enhanced EVD's spread to neighboring Sierra Leone, Liberia, and Cote d'Ivoire which are now a highlight of the 2013-2014 Ebola outbreak [61].

\subsection{Socio-Political Climate}

The porous borders are not only a result of deforestation, but also of historically strained government bodies [61]. Civil war and conflicts have impeded the development of Liberia, Sierra Leone and Cote d'Ivoire, which geographically border Guinea's forest (Figure 3) [61]. Political instability and fragility stimulated fleeing of refugees exacerbating the economic burden on resource poor nations [61]. Fluid borders, monitored by weak governments, enhanced the spread of EVD cases during the 2013-2014 outbreak, creating urgency for coordinated control and communication between the neighboring countries [61].

\subsection{Micronutrient Deficiency}

There is evidence suggesting that the Ebola Zaire virus creates a selenium (Se) demand on the infected host, in turn depleting the hosts Se stores in days $[63,64]$. Se, an essential anti-oxidant, is part of the glutathione peroxidase in blood and liver cells, and low Se levels are associated with oxidative stress, lipid peroxidation and cell death, all phenomena experienced by Ebola infected individuals [64]. The Ebola Zaire strain has shown to have 16 UGA selenocysteine codons, which are required to express selenoprotein, requiring 16 Se atoms per molecule [63]. 
The selenoproteins have been found to overlap the first 6 genes of the Ebola virus which all have selenocysteine (SeC) insertion sequences in their mRNAs [64]. It is interesting to note that the Ebola Reston strain does not contain the 16 UGA selenocysteine codons and does not create a Se demand in the human host, it is also nonvirulent in humans [63]. Se is normally found in a healthy human by inhibiting blood coagulation; the deficiency therefore is related to thrombosis, and hemorrhaging [63]. Studies indicate that dietary intake of Se inhibits Ebola viral replication yet the deficiency of Se provokes replication [64]. This suggests that survival of the Ebola virus via replication may be increased when faced by low Se concentrations (Figure 4) [64]. Another study suggests that the disabling of $\mathrm{T}$ cell function seen as a result of Ebola Zaire is similar to that seen in Se deficient hosts infected with influenza [65]. The role of the host's Se status and Ebola Zaire's virulence has not yet been established [65]. Se deficiency occurring during early development is linked to immature immune systems once the individual is fully developed [65].

Prolonged dry climates are related to individuals expressing hunger, which can be an expression of the host's Se status [65]. Malnutrition is an expression of Se deficiency, which is exacerbated by the Se-poor soil of the African landscape [65]. This is in part due to SO2 reacting with Se impeding plant absorption of Se, along with fossil fuel burning and acid rain leading to a decrease of Se in the ecosystem [64].

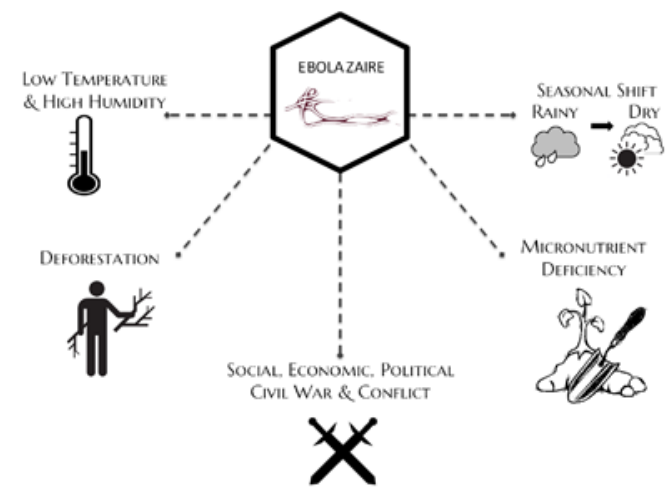

Figure 3. Possible Outbreak Triggers

Depiction of possible factors contributing to an Ebola Zaire outbreak. Shift from rainy to dry season, marks the beginning of most outbreaks [60]. Low temperatures and high humidity levels have been associated with almost all Ebola Zaire outbreaks [60]. Deforestation, a result of socio-economic decline drives humans into the forest allowing them greater contact with possibly infected wildlife species [61]. Thinning of the forest also leads to more porous borders between neighboring countries [61]. Micronutrient deficiency, specifically selenium deficiency, in early childhood produces weakened immune systems [63,64,66-73]

\section{Clinical Manifestations}

Early recognition of signs and symptoms of Ebola virus disease is essential for the prevention and eradication of EVD. The clinical presentation is attributable to both viral replication and host immune responses [13]. Signs and symptoms of EVD typically include: fever, fatigue, loss of appetite, vomiting, diarrhea, headache, abdominal pain, unexplained bleeding (Table 4) [74].

Table 4. Common Clinical Manifestations of EVD

$\begin{array}{cc}\text { Symptoms [74] } & \text { Symptom Frequency[20] } \\ \text { Fever } & 87.1 \% \\ \left.\text { (greater than } 38.6^{\circ} \mathrm{C} \text { or } 101.5^{\circ} \mathrm{F}\right) & 76.4 \% \\ \text { Fatigue } & 64.5 \% \\ \text { Loss of Appetite } & 67.6 \% \\ \text { Vomiting } & 67.6 \% \\ \text { Diarrhea } & 53.4 \% \\ \text { Headache } & 44.3 \% \\ \text { Abdominal pain } & <1 \%-5.7 \% \\ \text { Hemorrhagic symptoms } & 18 \% \\ \text { Unexplained bleeding }\end{array}$

Table 4. Most common EVD symptoms reported by EVD infected patients along with their frequencies [20]. The table highlights key time periods extracted from the New England Journal of Medicine's, Ebola Virus Disease in West Africa - The First 9 Months of the Epidemic and Forward Projections, compiled by the WHO response team [20]

EVD symptoms usually appear after an 8 to 10 day incubation period, yet can appear anywhere from 2 to 21 days from infection [74]. Patients infected with Ebola or Marburg virus initially present with similar nonspecific flu-like symptoms such as fever, chills, malaise, muscle pain, and headache making the initial diagnosis of EVD elusive $[7,75]$. EVD infected patients may present with a macropapular rash of varying erythema severity around day five [7]. After extensive viral replication occurs, systemic, vascular, and neurologic manifestations, along with necrosis of the liver, spleen, kidneys, contribute to the severity of the clinical profile of an EVD case [7]. In certain cases, the virus is lethal, with death of the infected patient occurring approximately 6 and 16 days postinfection [76]. Patients who die abruptly after the appearance of symptoms fail to develop an adequate immune response to the Ebola virus [74]. Some infected patients also display a so-called "light bulb" phenomenon, where a decrease in symptoms hints towards survival, instead patients abruptly die [77]. Contributing to the virus' lethality is multiple organ failure and severe cases of fatal septic shock syndrome [7]. Not all cases of EVD infected individuals succumb to death, notably some patients fully recover and are classified as survivors of EVD [74].

For adequate EVD transmission control, detection of early signs and symptoms via active and direct active monitoring is essential [78]. Active monitoring involves regular communication between state or local public health officials and exposed individuals allowing for early and reported detection of symptoms [78]. Exposed individuals are asked to self-monitor for EVD symptoms, especially the oncoming of a fever, by checking their temperature twice daily [78]. Active monitoring is dependent on self observation and regular communication between the EVD exposed and the local or state public health authorities [78].

Direct active monitoring, involves immediate detection of EVD symptoms by the local public health officials [78] This is achieved by active daily monitoring of cases placed in isolation for observation [78]. Both active and direct active monitoring are a means to immediately detect, isolate, evaluate and treat EVD infected individuals, in an 
effort to impede disease progression and prevent transmission by utilizing the power of early detection [78].

\section{Screening \& Early Detection Methods}

EVD is difficult to diagnose because early signs and symptoms resemble those of other diseases, such as typhoid and malaria. In response to the 2014 outbreak in West Africa, the Centers of Disease Control and Prevention (CDC) has provided recommendations for the evaluation and management of persons who may have been exposed to Ebola virus [79]. Its approach depends upon when the exposure occurred, if the exposure was high risk or low risk, and whether or not the individual is displaying signs and symptoms consistent with Ebola virus disease.

Health care providers should evaluate patients who have clinical findings consistent to Ebola virus disease and have had a possible exposure to Ebola virus as follows [79,80]:

Fever of greater than $38.6^{\circ} \mathrm{C}\left(101.5^{\circ} \mathrm{F}\right)$, and

Additional signs and symptoms such as severe headache, muscle pain, vomiting, diarrhea, abdominal pain, or unexplained hemorrhage, and

Risk factors within 21 days prior to the onset of the symptoms, such as contact with blood or other body fluids of a patient known to have or suspected to have Ebola virus; residence in or travel to an area where Ebola virus transmission is active; or direct handling of bats, rodents, or primates from endemic areas.

Testing of patients depends upon the likelihood that a patient was exposed to Ebola virus [79]. The CDC recommends testing for:

1. All patients with onset of fever within 21 days of having a high-risk exposure. A high-risk exposure includes any of the following:

Percutaneous or mucous membrane exposure or direct skin contact with body fluids of a person with a confirmed or suspected case of Ebola virus disease without appropriate personal protective equipment (PPE)

Laboratory processing of body fluids of suspected or confirmed Ebola virus disease cases without appropriate PPE or standard biosafety precautions

Participation in funeral rites or other direct exposure to human remains in the geographic area where the outbreak is occurring without appropriate PPE.

2. Persons with a high-risk exposure but without fever, only if there are other symptoms present and laboratory findings are unknown or abnormal such as platelet count $<150,000$ cells /microL and/or elevated transaminases).

3. Low-risk patients with fever and unknown or abnormal laboratory findings [79]. A low risk exposure includes any of the following:

Providing patient care or casual contact without highrisk exposure to Ebola virus disease patients in healthcare facilities in outbreak affected countries

Household members or other casual contact of an Ebola virus disease patient without high-risk exposures as described above

Persons who had direct unprotected contact with bats or primates from Ebola virus disease-affected countries.
If testing is indicated, the local or state health department should be contacted immediately and serum, plasma, or whole blood should be collected with a minimum volume of $4 \mathrm{ml}$ and shipped refrigerated or frozen on ice pack, or dry ice to the CDC or other specialized laboratories [79]. The sample should be taken by trained health personnel with extreme biosecurity measures and additional protective equipment (non-sterile gloves, masks, and goggles). This sample should be ideally taken at the hospital designated to handle cases compatible with Ebola virus diseases.

Infections are confirmed by various laboratory diagnostic methods. These include reverse transcriptionpolymerase chain reaction (RT-PCR), including real-time quantitative RT-PCR, antigen-capture enzyme-linked immunosorbent assay (ELISA), antigen detection by immunostaining, and IgG- and IgM-ELISA. Blood specimens usually begin to test positive using polymerase chain reaction-based diagnosis one day before symptoms appear. Detection of viral antigen by enzyme linked immunosorbent assay (ELISA) may be used as a confirmatory test for immediate diagnosis. Serologic diagnosis by the detection of specific IgM and IgG antibodies is suitable for patients in a relatively late stage of illness. For clinical practice, PCR is generally the most useful test, as patients are more likely to be positive during the symptomatic and infective period of the disease. Overall, the diagnosis of EVD must be sensitive, specific, and reliable because misdiagnosis may bring huge turmoil to society. Therefore, it must rely on multiple diagnostic assays [81].

In West Africa, tests have to be performed in laboratories that may not be local. Therefore, it can take days to get the results, delaying care. More diagnostic sites are needed to tackle the disease [82]. The use of rapid tests would be beneficial to quickly separate patients needing quarantine, creating a safe healthcare environment by efficiently utilizing quarantine resources [83]. A rapid test can also be used at borders and airports for health officials to safely allow or restrict access from a country with a known outbreak, enabling of much-needed supplies, workers, and resources safely [83]. Rapid testing allows for early detection of EVD, and allows for the implementation of various protective barriers to be put in place between the infected and the general population [83].

Testing within laboratories could also potentially put vital healthcare workers, laboratory testing personnel, at risk for contracting Ebola [84]. A recent study assessing the risk of microdroplet or aerosol generation (routes not yet proven to cause EVD) during laboratory testing of Ebola infected materials, took place at the University of Nebraska Medical Center [84]. Highest risk was found to be associated with exposure to eyes and mucous membranes of laboratory professionals, determining that testing of possible Ebola infected serum may only be performed with closed manual or automated chemistry and hematology analyzers outside of a BSL-3 containment laboratory [84]. The risk associated with performing certain serum assays to support an EVD infected patient was also studied [84]. Findings suggest that fibrinogen levels, procalcitonin, and cross matching of blood assays are unsafe, if required alternatives should be discussed with the ordering physician [84]. The study highlights the infectious nature of Ebola specimens, and delineates the 
extent to which precautions should be practiced by those handling the specimens [84]. Contracting EVD in a laboratory setting would strain the capacity of the laboratory, associated hospital, and personnel in providing optimal care [84].

\section{Supportive \& Experimental Treatment Options}

Supportive care is the mainstay of treatment for patients with symptomatic EVD [85]. Symptomatic treatment focuses on aggressive volume and electrolyte balancing, oral and intravenous nutrition, and pain management [85]. Aggressive fluid replacement is key to effective treatment, since patients presenting with diarrhea are likely to become hypovolemic [86]. Ringer's lactate is preferred over normal saline, as it does not result in hyperchloremia associated mortality, which is often witnessed with normal saline use [86]. Studies suggest that colloid solutions, human albumins, and synthetic starches are more likely associated with adverse renal outcome,s and provide no benefit to the EVD infected patient [86]. Anticoagulants should also be administered to prevent or control disseminated intravascular coagulation, and clotting factors to control bleeding [85]. Diagnosis and treatment of concomitant infections, including malaria and typhoid, are also important aspects of patient care [85].

Since 1976 more than 15 Ebola outbreaks have erupted in Sub-Saharan Africa with no established treatment options to date, yet promising developments are being made at the preclinical level which are summarized in Table $5[87,88]$. The most promising candidate at this point is Zmapp, a combination drug consisting of three monoclonal antibodies, c13C6 from MB-003 along with two humanized Zmab monoclonal antibody derivatives, c2G4 and C4G7 [89]. Zmab itself is a combination of three monoclonal mouse antibodies M1H3, m2G4, m4G7, which targets the surface glycoprotein of the Ebola virus [89]. When testing Zmab alone in four macaque monkeys 48 hours post-infection, only two survivors remained [89] Tested in 2012 in rhesus macaques, Zmapp is a leading candidate in the race to find a cure $[88,89]$. Studies of Zmapp in nonhuman primates have established that it confers protection only when administered 24 to 48 hours post-infection [90]. Safety and efficacy trials have not yet been conducted in humans [90]. However, under FDAs “expanded access" policy, Zmapp was administered to two EVD infected healthcare workers of American nationality [91,92]. The pair contracted EVD in Liberia, and were transported to Atlanta, GA for treatment [91]. Despite lacking clinical data, the two infected individuals showed signs of improvement after administration [90]. Whereas a Spanish patient who received Zmapp was reported deceased two days after being administered Zmapp for EVD treatment [89]. Administration of Zmapp sparked ethical controversy, with some questioning why the options were not made more widely available in Africa, and others concerned that administering an experimental drug without safety data would be unethical [92,93].

Another promising candidate is Favipiravir, a pyrazinecarboxamide derivative T-705, approved against influenza in Japan [94]. This agent by selectively inhibiting viral RNA dependent RNA polymerase has shown antiviral activity against negative and positive stranded RNA viruses [94]. A recent study demonstrated that in T-705 treated mice, no virus was detectable irrespective of the dose [94]. In addition, all surviving mice developed EBOV-specific antibodies and CD8 T cells [94]. The study concluded that Favipiravir induces rapid virus clearance, reduces disease severity, and prevents lethal outcomes in animal model [94]. It confers protection in animals if treatment was initiated 6 days after infection. One case, of a French nun who contracted Ebola while volunteering in Liberia, has recovered with Favipiravir treatment [95].

TkM-Ebola, a small interfering RNA (siRNA) targeting the Zaire Ebola L polymerase, membrane-associated protein (VP24) and Zaire Ebola polymerase complex protein (VP35), has protected non-human primates against ZEBOV [96]. Study showed two of the three rhesus monkeys were protected from ZEBOV when given four postexposure treatments; however, all macaques given seven postexposure treatments survived [96]. The Federal Food and Drug Administration (FDA) placed a hold on the Phase I clinical trial, because of reports related to unsafe levels of cytokine release, but have since modified it to partial clinical hold allowing for special use in Ebola infected patients [89]. One case, Dr. Richard, was treated with TKM-Ebola, and survived the virus [97]. Currently, the drug company Tekmira is in the process of making the drug available to West Africans through a clinical trial [97].

Table 5. Experimental Anti-Ebola Drugs \& Vaccines

\begin{tabular}{|c|c|c|c|c|}
\hline Drugs & Description & Mechanism of Action & Test species & Developer \\
\hline TkM-Ebola & $\begin{array}{l}\text { Small interfering RNA } \\
\text { (siRNA) [96] }\end{array}$ & $\begin{array}{c}\text { Targets the Zaire Ebola L polymerase, } \\
\text { membrane-associated protein (VP24) and } \\
\text { Zaire Ebola polymerase complex protein } \\
\text { (VP35[96] [96]) }\end{array}$ & Monkeys [101] & $\begin{array}{l}\text { Tekmira } \\
\text { Pharmaceuticals } \\
\text { (Canada) }[101]\end{array}$ \\
\hline Brincidofovir & $\begin{array}{l}\text { A modified analog of } \\
\text { Cidofovir [98] }\end{array}$ & $\begin{array}{c}\text { Inhibits replication of RNA viruses based } \\
\text { on cell culture [98] }\end{array}$ & $\begin{array}{c}\text { In vitro activity } \\
{[102]}\end{array}$ & Chimerix (USA) [102] \\
\hline Favipiravir & $\begin{array}{c}\text { A pyrazinecarboxamide } \\
\text { derivative T-705 [94] }\end{array}$ & $\begin{array}{c}\text { Selectively inhibit viral RNA dependent } \\
\text { RNA polymerase [94] }\end{array}$ & Mouse [101] & $\begin{array}{l}\text { Toyama Chemical } \\
\text { (Japan) [101] }\end{array}$ \\
\hline Zmapp & $\begin{array}{l}\text { Combination of three } \\
\text { monoclonal antibodies [89] }\end{array}$ & Unknown & $\begin{array}{l}\text { Monkeys; patients } \\
\text { [101] }\end{array}$ & $\begin{array}{l}\text { Mapp pharmaceutical } \\
\text { (USA) [101] }\end{array}$ \\
\hline \multicolumn{5}{|c|}{ Vaccines } \\
\hline CAd3-ZEBOV & $\begin{array}{c}\text { Genetically engineered } \\
\text { Chimp Adenovirus type } 3 \\
{[101]}\end{array}$ & $\begin{array}{l}\text { Expressed the GP of Zaire and Sudan } \\
\text { Species of Ebola Virus [101] }\end{array}$ & Phase I[101] & GlaxoSmithKline (UK) [101] \\
\hline VSV-ZEBOV & $\begin{array}{c}\text { Genetically modified } \\
\text { vesicular stomatitis virus } \\
{[101]}\end{array}$ & Express Ebola GP [101] & Phase I [101] & $\begin{array}{l}\text { National Microbiology } \\
\text { Laboratory (Canada) [101] }\end{array}$ \\
\hline
\end{tabular}


Table 5. Experimental Anti-Ebola Drugs \& Vaccines Highlights the potential anti-Ebola drugs or vaccines along with their mechanism of actions and stages of development

Brincidofovir, a modified version of the antiviral Cidofovir, inhibits replication of DNA viruses including poxviruses and herpesviruses [98]. This agent not only inhibits replication of DNA viruses, but was also found to inhibit Ebola viral replication in cell culture [98].

Currently indicated for treatment of cytomegalovirus infections, the FDA has allowed the use of Brincidofovir as a treatment option for patients with EVD based on in vitro data [89,99]. Brincidofovir was used to successfully treat Dr. Craig Spencer and Ashoka Mukpto [100].

Not only did Dr. Craig Spencer receive experimental Brincidofovir, he also received blood plasma from an EVD survivor [55]. Historically, convalescent-phase human serum has been successful in the treatment of a few EVD cases [103]. During the 1995 Ebola outbreak in Kikwit, Democratic Republic of Congo, convalescent blood was administered to eight patients and seven of the eight patients survived [103]. However, since the study included a small number of patients and lacked a control group, no conclusion could be made concerning whether the treatment alone contributed to improvement in clinical outcomes [103]. Dr. Kent an EVD survivor, received blood transfusion from an EVD surviving teenager, and in turn donated his blood to Dr. Richard, Ashoka Mupko, and Nina Pham, all of whom are now EVD survivors of the current West African outbreak [97].

No clinical trials exist to date that prove blood transfusions from survivors are an effective Ebola treatment, but a few cases have led the WHO to believe that convalescent serum might be a good option for Ebola treatment [97]. According to the WHO guidelines, patients who have recovered from EVD, and have been discharged from Ebola treatment centers could be potential donors, from 28 days after their day of discharge [100]. This is to ensure that the fresh or frozen convalescent plasma being collected via plasmapheresis is free of EVD and other viruses [104]. Providers must ensure that donor's hemoglobin levels are within normal limits [104]. Evidence suggests that there may be an advantage to the recipient, if the donor is from the same geographical region as the EVD infected [104]. Convalescent blood appears to be a viable and sole treatment option for EVD infected patients, and the need has been recognized by the WHO, who have now placed whole and labile blood on the Essential Medicines List [104].

\section{Proactive Steps to Eliminate Ebola}

\subsection{Production \& Dissemination of Vaccines}

Currently no licensed vaccines are available for Ebola viruses [89]. However in recent years, a number of vaccine candidates that are highly protective in nonhuman primates have been developed (Table 5). Among these vaccines are recombinant adenovirus, recombinant vesicular stomatitis viruses, and virus like particles [105]. Ebola virus vaccines are divided into non-replicating and replicating vaccines. Non-replicating viral vectors carry deletions of genes and in order for these vaccines to be efficacious, higher doses are required [105]. Replication Ebola virus vaccines are generated with the gene encoding the immunogen integrated into their genome; these vaccines are efficacious, yet are replicating making human safety a primary concern [105].

From the non-replicating virus, recombinant adenovirus-based vaccines have been used to achieve protection against different strains of Ebola virus [105]. A non-replicating viral vectored Ebola vaccine is the recombinant Chimpanzee Adenovirus Serotype 3 Vectored Ebola Vaccine (CAd3), which expresses the glycoprotein of the ebola virus [89]. Based on studies showing protection in non-human primates, this vaccine is progressing into phase I clinical trial [89]. CAd3 is currently being tested in both bivalent and monovalent form. Three different doses of monovalent form will be used in the nonrandomized, open-label study and will be tested in 60 volunteers [89]. The bivalent form will be studied in 20 adults volunteers who will be receiving two different doses [89]. The two studies will examine safety, immunogenicity and side effects.

Another promising vaccine is the recombinant VSV(rVSV), which is a replicating Ebola virus vaccine that conferred $100 \%$ protection in rodents and nonhuman primates after a single vaccination [106]. Additionally, rodents and nonhuman primates were partially protected postexposure by a single dose of this vaccine and immunocompromised SHIV-infected rhesus macaques were partially protected preexposure.[106] Virus isolation or RT-PCR did not detect ZEBOV replication after challenge and vaccinated animals did not show any signs of disease [105]. One study showed that CD4+ T cells are not required in rVSV-mediated protection against ZEBOV infection; however, ZEBOV-GP-specific antibodies were critical for survival [106]. The phase 1 trial is expected to begin soon in the United States. The immunogenicity results will ideally be compared with the outcomes obtained with the GSK-NIAID vaccine [107]. 800 vials of rVSV was donated to WHO by the government of Canada and the trial is expected to expand to European and subSaharan African sites [107].

Currently, researchers are assessing the role of Cytomegalovirus (CMV) as a disseminating vaccine. Since this herpes virus is highly immunogenic, a recombinant CMV expressing a single T-cell from ZEBOV NP was used to fully protect mice after two vaccinations [105]. Efficacy and safety studies will be required, before these vaccines could be considered for use.

Vaccine development provides an avenue for mitigating EVD outbreaks and reducing transmission, yet faces the challenges of timely production and unknown efficacy [107]. In producing successful vaccines, it is essential to understand that doses may not provide complete protection to a population [107]. This in turn, this draws attention to the significance of promoting risk and infection reducing behavioral strategies, in conjunction with strengthening the healthcare infrastructure to provide adequate supportive therapy for communities [107].

\subsection{Practicing Prevention and Precaution to Control Infection}


In the absence of effective treatment and human vaccines, raising awareness of the risk factors and protective measures among individuals, is the only way to reduce human infection and death. Several strategies have been implemented by WHO to reduce the risk of transmission [24]. Animals should be handled with gloves and other appropriate protective clothing. In addition, animal products should be thoroughly cooked before consumption to reduce the risk of wildlife-to-human transmission. Since human-to-human transmission is by contact with infected bodily fluids, gloves and appropriate personal protective equipment should be worn when taking care of ill patients and regular hand washing is required after visiting patients in hospital, as well as after taking care of patients at home. Funeral practices have to be modified to prevent contact with body fluids of people who have died from EVD, until the outbreak is controlled [108]. This might be culturally sensitive issue that requires culturally appropriate outreach and education [108]. From the public health perspective, these strategies have been successful in the past in controlling Ebola virus outbreaks.

\subsection{Priming Health care Facilities to Protect Patients and Providers}

It is not always possible to identify patients with Ebola virus early because initial symptoms may be non-specific. Therefore, it is important that health care workers at all level apply standard precautions consistently. The CDC and WHO have issued recommendations for the prevention of EVD transmission in U.S. hospitals [30,109]. If a patient is suspected or known to have Ebola virus disease, patient should be isolated to mitigate further spread of disease. Ideally an isolation area should have a toilet, good ventilation, screened windows and restricted access. Health care providers entering the patient's room should wear gloves, gown, eye protection, and a facemask. Diligent environment cleaning, disinfection, safe handling of potentially contaminated virus is of paramount importance, as blood, sweat, vomit, feces, and urine represents potentially infectious materials [110,111].

Effectively controlling Ebola requires that healthcare facilities in West Africa exhibit strong infrastructural foundations and provide access to Ebola specific treatment centers [112]. On July 31, 2014 WHO allocated \$100 million, along with the World Bank contributing \$200 million in funds to be used for establishing strong healthcare infrastructure in West Africa, highlighting that the epidemic is a direct result of gaps in the healthcare system [113]. As of October 31, 2014 there are only 15 Ebola treatment centers providing 1,047 beds, two in Guinea, seven in Sierra Leone, and six in Liberia, to which the WHO plans to add 41 additional centers, concentrating their efforts in Liberia [112]. Furthermore, the U.S. is assisting with laboratory assistance, preparing 24 laboratories for testing of possible EVD infected specimens [112]. Not only are Ebola treatment units important for patients, but data suggests that health care workers treating Ebola outside of Ebola treatment units are at an increased risk for EVD in Liberia [29]. On November 5, 2014 the Obama Administration requested $\$ 6.18$ billion from Congress, of which $\$ 4.64$ to be used immediately and $\$ 1.54$ billion as a Contingency Fund to battle the evolving nature of the epidemic [114]. The amount requested will be used to bolster the public health infrastructure, provide for vaccine and therapeutic drug testing, and increase national and global security via early detection and containment of outbreaks [114]. The requested $\$ 4.64$ billion will be distributed as $\$ 2.43$ billion to the Department of Health and Human Services, \$1.98 billion to the U.S. Agency for International Development for global coordination to control the epidemic, \$127 million to the Department of State to assist in proper evacuation of cases, and \$112 million to the Department of Defense to apply new technologies in fighting the Ebola virus [114]. Of the Department of Health and Human services $\$ 2.43$ billion, $\$ 1.83$ billion will be allocated to the CDC for early detection of ebola, \$333 million to the Public Health and Social Services Emergency fund for enabling immediate response to infectious disease patients by training and establishing over 50 Ebola treatment centers, \$238 million to the National Institute of Health to advance drugs through clinical trials, and \$25 million to the Food and Drug Administration for post-market surveillance of Ebola therapeutics [114].

\subsection{Preparing Healthcare Providers to Challenge EVD}

Coordinated public health actions are essential to stop and reverse the spread of Ebola [78]. The CDC is working with other U.S government agencies, the World Health Organization and other domestic and international partners in an international response to the current outbreak in West Africa. CDC has deployed several public health experts to the affected countries to help coordinate technical assistance and control activities with partners [115]. Health care providers are also sent to West Africa to help counter the outbreak; however, providers are at highest risk of contracting the virus since care are often provided in facilities that lack reliable supplies of electricity and running water. As of August 11, 2014 health care workers have represented nearly 10 percent of the cases fatalities, significantly impairing the ability to respond to the outbreak in countries, which already face a severe shortage of physicians [116]. WHO reported that the loss of many health workers was making it difficult to provide sufficient numbers of foreign medical staff [30].

Nevertheless, international health organizations should assist with mobilizing resources to improve the training of healthcare professionals in the affected countries. Early recognition is critical to controlling the spread of Ebola virus [78]. Health care providers should evaluate every patient's epidemiologic risk, including a history of travel to a country with widespread Ebola virus transmission or contact with a person with symptomatic Ebola to prevent future spread of this deadly virus [78]. Pharmacists should be trained to provide basic information to the public, including ways to minimize the risk of transmission and to report suspected cases. Pharmacists, both in the affected countries and internationally, should reflect on what role their profession should play in epidemics like this [117]. In many countries, pharmacies are an initial point of care for the community; thus, pharmacies are the best places to implement community-based interventions. To every outbreak of every disease there is a turning point to cease the spread of the disease, and with this current outbreak of 
Ebola disease all help with advanced healthcare professionals are needed to bring a turning point to cease this deadly epidemic of Ebola virus disease.

\section{Ethical Controversies}

\subsection{Quarantine \& Isolation}

Prior to 2014, Ebola-Reston made its way to the United States, notably in 1989, 1990, and 1996, through the importation of infected monkeys $[118,119]$. These isolated events resulted in no lethal transmissions between primates and humans, and remained contained as a result of CDC enacted quarantine practices [120]. The CDCs practice to quarantine those with hemorrhagic fevers is in response to an episode of Marburg virus in 1967 [120]. Quarantine has proved through practice, that it limits the spread of infection, legislatively protecting the health of the American people [120]. On the contrary, issuing a quarantine with incomplete information or understanding of a scenario may put individuals at greater risk, as was witnessed in the case of the four individuals in Dallas, TX [121]. These four individuals were contacts of infected Thomas Eric Duncan, and suspect Ebola cases that were quarantined to remain in their decontaminated apartment for 48 hours, increasing their exposure to hazardous contaminated materials [121]. The scenario has highlighted gaps within international healthcare systems response to public health emergencies.

The West African population is facing novel challenges as the outbreak is spreading through major cities, data from the first nine months of the epidemic show that of those who are 15 years of age, who make up $43 \%$ of the population, only $13 \%$ became infected [122,123]. A segment of the population highly affected is one which is often a underrepresented facet of the healthcare system, children [123]. The clinical presentation of an individual with Ebola is unfortunately masked by the presentation of non-specific illnesses afflicting children year round (eg. fever, fatigue, etc) [123]. The communication barriers between children and healthcare providers further blur the conditions for diagnosis and significantly put pediatric healthcare providers at risk [123]. If diagnosing a child as infected, isolation may require the regular presence of a caregiver, usually a household member, highlighting the need for effective guidelines in managing infected children [123]. Though it has been found that Ebola can be detected in semen for a maximum of 91 days [60]. There is limited data of transmission from mother to the fetus during pregnancy and post-delivery, and transmission from mother to infant via breast milk is undetermined [123].

\subsection{Experimental "Treatment"}

During the 1976 Ebola virus outbreak, the government of Zaire (Democratic Republic of Congo) requested a team of foreign healthcare workers and scientists to assist in containing the outbreak [4]. It was established that both Zairean and international healthcare workers would be treated equally, if infected. Yet, the geographic location of treatment was now open to discussion. Treating the healthcare worker locally would result in saved time and decreased exposure to uninfected individuals; whereas treating internationally could delay treatment, place a higher number of individuals at risk for infection, but provide the possibility for access to superior treatment options [4]. This very dilemma has resurfaced in 2014, in the case of the four U.S. aid workers who were transported to Atlanta, GA to receive experimental drug therapy $[4,124]$. The transport of aid workers to their native countries for treatment has been questioned [11]. This very act creates the image of a non-existing advantage for those witnessing the removal of workers from the inadequate health care system of West Africa, perpetuating pre-existing notions of distrust and inferiority, and sparks fear of the unknown risk and exposure to the disease in citizens of developed nations [11].

Experimental therapies have questionable benefit versus risk profiles, as they have only been tested in primates, and administered during the current epidemic [11]. Six individuals have been administered Z Mapp, an experimental agent, of which two have died; the limited data neither discounts its efficacy nor promotes its safe use [11]. Therapeutic agents are administered under the premise of "in the first place, does no harm" yet in this situation we have no data to support an agent's short or long term effects [11]. The experimental therapy has no research supporting its use, and is employed concurrently with an outbreak creating a circumstantial clinical trial, which may endanger the lives of whom it intends to benefit [11]. This is based on the FDA's ruling on making therapy tested in at least 2 animals made available on "compassionate grounds" [113]. The practice of rushing an experimental agent to control an epidemic is debatable as there is no data to suggest the drug's positive or negative impact on transmission or containment of an epidemic [11]. One possible pitfall of providing untested therapy is that may amplify and reignite a deep rooted notion of distrust towards the Western approach to medicine, which cascades through communities and ultimately results in non-compliance, perpetuating the Ebola epidemic [11]. Furthermore, the therapy during the current outbreak was made available to infected healthcare workers of developed nations, of which supplies have been exhausted [11].

Shifting attention from the research and development of experimental therapy which has proven to exhibit no definite cure or benefit, funds are being allocated towards prevention and non-pharmaceutical interventions [113].

In regards to the effects of potential treatment therapies, it is important to note that children are not members of the testing samples of clinical trials, and therefore are not a viable patient population eligible for a potential cure [123]. A study of the EBOLA SUDV strain has revealed an increased rate of death among children under the age of 5 [122]. Furthermore, pediatric patients exhibit higher biomarker expression of IL-10, IP-10, RANTES, sICAM, sVCAM, and PAI-1 when compared to adults [122]. Of the pediatric biomarkers, only increased levels of RANTES were found to be related to pediatric survival [122]. Survival of SUDV infected pediatric patients is attributed to increased SUDV-specific T-cell mediated response, due to activation and recruitment of T-cells by RANTES [122]. This phenomenon is not experienced by adults, who express lower levels of RANTES [122]. Data from pediatric and adolescent patients associates higher mortality with high levels of sICAM, sVCAM, and PAI-1, 
all endothelial responses which do not contribute to death in the adult population [122]. A comparison of biomarker correlates between pediatric and adult patients reveals distinct differences in pathophysiological immune responses, allowing for the possibility of novel treatment targets, agents, and regimens for use specifically in the EVD infected pediatric population [122].

\section{Closing Remarks}

Since its discovery in 1976, Ebola has emerged as one of the deadliest forms of hemorrhagic fever. Transmission among humans occurs through the exchange of blood and body secretions [2]. Possible triggers associated with outbreaks include low temperatures, high humidity, seasonal change and its relationship with animal behaviors, and socio-economic decline leading to deforestation [60], [61]. Outbreaks of Ebola are commonly associated with inadequate medical preventive measures, an indirect result of impoverished conditions. The 2013-2014 West African Ebola epidemic is notably the largest in the history of the virus. Contributing to the virus' success is the delayed identification of the outbreak, which initially spread unsuspectedly to neighboring regions [23]. The sociopolitical climate of West Africa has resulted in the deterioration of the regions healthcare system infrastructure, creating an Ebola outbreak of greater magnitude than previously observed [23]. The origin of the current outbreak possesses a geographical advantage, once limited to rural areas of Central Africa; it has now made its debut in densely populated regions [23]. The virus has emerged in a populous region of Guinea, surrounded by three countries with similar socio-cultural practices and porous borders, contributing to its effective transmission [23]. While multiple candidate vaccines and antiviral therapies are currently in development, preventative public health interventions involving risk communication and implementation of proper protective principles prove to be a means to mitigate the spread of EVD.

\section{Acknowledgement}

The authors would like to thank Tracy Osei Agyemang, Pharm.D. candidate at Touro College of Pharmacy for her assistance in researching information.

\section{Statement of Competing Interests}

The authors have no competing interests.

\section{List of Abbreviations}

Ribonucleic Acid: RNA; Interferon: IFN; Retinoic Acid-Inducible Gene: RIG; Protein Kinase R:PKR; Coat Protein: COP; Endosomal Sorting Complexes Required For Transport: ESCRT; Natural Killer: NK; Confidence Interval: CI; Centers For Disease Control And Prevention: CDC; Biosafety Level: BSL; Ebola Virus: EBOV; Sudan ebolavirus: SUDV; Interleukin: IL; Interferon-inducible protein: IP; Regulated on Activation, Normal $\mathrm{T}$ Cell
Expressed and Secreted: RANTES; soluble intercellular adhesion molecule: sICAM; soluble vascular cell adhesion molecule: sVCAM; Plasminogen activator inhibitor: PAI.

\section{References}

[1] "About Ebola Hemorrhagic Fever| Ebola Hemorrhagic Fever | CDC.” [Online]. Available: http://www.cdc.gov/vhf/ebola/about.html. [Accessed: 02-Nov2014]

[2] "WHO | Ebola virus disease," Oct. 2014 [Online]. Available: http://www.who.int/mediacentre/factsheets/fs103/en/

[3] D. Gatherer, "The 2014 Ebola virus disease outbreak in West Africa," J. Gen. Virol., vol. 95, no. Pt 8, pp. 1619-1624, Aug. 2014.

[4] J. G. Breman and K. M. Johnson, "Ebola Then and Now,” N. Engl. J. Med., Sep. 2014 [Online].

[5] R. A. Fowler, T. Fletcher, W. A. Fischer 2nd, F. Lamontagne, S. Jacob, D. Brett-Major, J. V. Lawler, F. A. Jacquerioz, C. Houlihan, T. O’Dempsey, M. Ferri, T. Adachi, M.-C. Lamah, E. I. Bah, T. Mayet, J. Schieffelin, S. L. McLellan, M. Senga, Y. Kato, C. Clement, S. Mardel, R. C. Vallenas Bejar De Villar, N. Shindo, and D. Bausch, "Caring for critically ill patients with ebola virus disease. Perspectives from west Africa," Am. J. Respir. Crit. Care Med., vol. 190, no. 7, pp. 733-737, Oct. 2014.

[6] WHO| World Health Organization, "EBOLA RESPONSE ROADMAP SITUATION REPORT,” Nov. 2014 [Online]. Available:

http://apps.who.int/iris/bitstream/10665/141468/1/roadmapsitrep_ 12Nov2014_eng.pdf

[7] Y. Cheng, Y. Li, and H. J. Yu, "Ebola virus disease: general characteristics, thoughts, and perspectives," Biomed. Environ. Sci., vol. 27, no. 8, pp. 651-653, Aug. 2014.

[8] "WHO | Statement on the 1st meeting of the IHR Emergency Committee on the 2014 Ebola outbreak in West Africa," Nov. 2014 [Online]. Available: http://www.who.int/mediacentre/news/statements/2014/ebola20140808/en/

[9] M. Baker, "Bat's immunity may hold key to preventing future Ebola outbreaks," Ecos, 2014 [Online]. Available: http://www.ecosmagazine.com/paper/EC14254.htm

[10] humans.txt, "Infectious Disease Index-Ebola virus | MSDSonline."

[11] G. K. Donovan, "Ebola, epidemics, and ethics-what we have learned," Philos. Ethics Humanit. Med., vol. 9, no. 1, p. 15, Oct. 2014.

[12] J. Olejnik, E. Ryabchikova, R. B. Corley, and E. Mühlberger, "Intracellular events and cell fate in filovirus infection," Viruses, vol. 3, no. 8, pp. 1501-1531, Aug. 2011.

[13] A. S. Kondratowicz and W. J. Maury, "Ebolavirus: a brief review of novel therapeutic targets," Future Microbiol., vol. 7, no. 1, pp. 1-4, Jan. 2012.

[14] S. K. Gire, A. Goba, K. G. Andersen, R. S. G. Sealfon, D. J. Park, L. Kanneh, S. Jalloh, M. Momoh, M. Fullah, G. Dudas, S. Wohl, L. M. Moses, N. L. Yozwiak, S. Winnicki, C. B. Matranga, C. M. Malboeuf, J. Qu, A. D. Gladden, S. F. Schaffner, X. Yang, P.-P. Jiang, M. Nekoui, A. Colubri, M. R. Coomber, M. Fonnie, A. Moigboi, M. Gbakie, F. K. Kamara, V. Tucker, E. Konuwa, S. Saffa, J. Sellu, A. A. Jalloh, A. Kovoma, J. Koninga, I. Mustapha, K. Kargbo, M. Foday, M. Yillah, F. Kanneh, W. Robert, J. L. B. Massally, S. B. Chapman, J. Bochicchio, C. Murphy, C. Nusbaum, S. Young, B. W. Birren, D. S. Grant, J. S. Scheiffelin, E. S. Lander, C. Happi, S. M. Gevao, A. Gnirke, A. Rambaut, R. F. Garry, S. H. Khan, and P. C. Sabeti, "Genomic surveillance elucidates Ebola virus origin and transmission during the 2014 outbreak,” Science, vol. 345, no. 6202, pp. 1369-1372, Sep. 2014.

[15] P. D. Walsh, R. Biek, and L. A. Real, "Wave-like spread of Ebola Zaire,” PLoS Biol., vol. 3, no. 11, p. e371, Nov. 2005.

[16] P. Ramanan, R. S. Shabman, C. S. Brown, G. K. Amarasinghe, C. F. Basler, and D. W. Leung, "Filoviral immune evasion mechanisms," Viruses, vol. 3, no. 9, pp. 1634-1649, Sep. 2011.

[17] J. D. Cook and J. E. Lee, "The secret life of viral entry glycoproteins: moonlighting in immune evasion," PLoS Pathog., vol. 9, no. 5, p. e1003258, May 2013.

[18] G. Chowell and H. Nishiura, "Transmission dynamics and control of Ebola virus disease (EVD): a review,” BMC Med., vol. 12, no. 1, p. 196, Oct. 2014. 
[19] T. C. Young, "The Journal of Global Health» Comparison of Two Ebola Hemorrhagic Fever Outbreaks," The Journal of Global Health. [Online]. Available: http://www.ghjournal.org/comparison-of-two-ebola-hemorrhagicfever-outbreaks/. [Accessed: 29-Oct-2014]

[20] WHO Ebola Response Team, "Ebola virus disease in West Africa-the first 9 months of the epidemic and forward projections," $N$. Engl. J. Med., vol. 371, no. 16, pp. 1481-1495, Oct. 2014.

[21] J. Legrand, R. F. Grais, P. Y. Boelle, A. J. Valleron, and A. Flahault, "Understanding the dynamics of Ebola epidemics," Epidemiol. Infect., vol. 135, no. 4, pp. 610-621, May 2007.

[22] T. House, "Epidemiological dynamics of Ebola outbreaks," Elife, vol. 3, Sep. 2014 [Online].

[23] M. Ki, "What do we really fear? The epidemiological characteristics of Ebola and our preparedness,” Epidemiol. Health, vol. 36, p. e2014014, Aug. 2014.

[24] “WHO | Ebola virus disease,” Oct. 2014 [Online]. Available: http://www.who.int/mediacentre/factsheets/fs103/en/

[25] "Transmission | Ebola Hemorrhagic Fever | CDC." [Online]. Available: http://www.cdc.gov/vhf/ebola/transmission/index.html. [Accessed: 27-Oct-2014]

[26] A. M. Casillas, A. M. Nyamathi, A. Sosa, C. L. Wilder, and H. Sands, "A current review of Ebola virus: pathogenesis, clinical presentation, and diagnostic assessment,” Biol. Res. Nurs., vol. 4, no. 4, pp. 268-275, Apr. 2003.

[27] "CDC Telebriefing on Ebola outbreak in West Africa | CDC Online Newsroom | CDC.” [Online]. Available: http://www.cdc.gov/media/releases/2014/t0728-ebola.html. [Accessed: 27-Oct-2014]

[28] Y. Allaranga, M. L. Kone, P. Formenty, F. Libama, P. Boumandouki, C. J. I. Woodfill, I. Sow, S. Duale, W. Alemu, and A. Yada, "Lessons learned during active epidemiological surveillance of Ebola and Marburg viral hemorrhagic fever epidemics in Africa," East Afr. J. Public Health, vol. 7, no. 1, pp. 30-36, Mar. 2010.

[29] "CDC Releases New Reports on Ebola Cases in Liberia and the United States | CDC Online Newsroom | CDC.” [Online]. Available: http://www.cdc.gov/media/releases/2014/p1114-ebolaliberia.html. [Accessed: 14-Nov-2014]

[30] "WHO | Unprecedented number of medical staff infected with Ebola," Aug. 2014 [Online]. Available: http://www.who.int/mediacentre/news/ebola/25-august-2014/en/

[31] F. R. Lashley and J. D. Durham, Emerging Infectious Diseases: Trends and Issues, Second Edition, 2 edition. Springer Publishing Company, 2007.

[32] M. Kiskowski, "Description of the Early Growth Dynamics of 2014 West Africa Ebola Epidemic,” arXiv [q-bio.PE], 20-Oct2014.

[33] "Free Vector Graphic: Monkey, Animal, Silhouette, Tree-Free Image on Pixabay-32427.” [Online]. Available: http://pixabay.com/en/monkey-animal-silhouette-tree-32427/. [Accessed: 14-Nov-2014]

[34] "Free Vector Graphic: Skull, Crossbones, Surgical Mask-Free Image on Pixabay-309032.” [Online]. Available: http://pixabay.com/en/skull-crossbones-surgical-mask-309032/. [Accessed: 14-Nov-2014]

[35] ousia, "Clipart-Family (b\&w version).”.

[36] “File:Home Icon.svg-Wikimedia Commons.” [Online]. Available: http://commons.wikimedia.org/wiki/File:Home_Icon.svg. [Accessed: 14-Nov-2014]

[37] “File: Simple Globe.svg-Wikimedia Commons.” [Online]. Available:

http://commons.wikimedia.org/wiki/File:Simple_Globe.svg. [Accessed: 14-Nov-2014]

[38] "Travel Background for Powerpoint | Backgrounds For PowerPoint." [Online]. Available: http://backgroundsforpowerpoint.org/travel-backgroundpowerpoint. [Accessed: 14-Nov-2014]

[39] "Free Vector Graphic: Bat, Dracula, Silhouette, Mammal-Free Image on Pixabay-24578.” [Online]. Available: http://pixabay.com/en/bat-dracula-silhouette-mammal-24578/. [Accessed: 14-Nov-2014]

[40] "Free Vector Graphic: Man, Men, Human, Wc, Toilet, SymbolFree Image on Pixabay-99040.” [Online]. Available: http://pixabay.com/p-99040/?no_redirect. [Accessed: 15-Nov2014]

[41] "2014 Ebola Outbreak in West Africa | Ebola Hemorrhagic Fever CDC.” [Online]. Available: http://www.cdc.gov/vhf/ebola/outbreaks/2014-westafrica/index.html. [Accessed: 27-Oct-2014]

[42] "Ebola Crisis Triggers Health Emergency," Drug Discovery \& Development. [Online]. Available: http://www.dddmag.com/news/2014/07/ebola-crisis-triggershealth-emergency. [Accessed: 27-Oct-2014]

[43] Denise Grady And, “Tracing Ebola's Breakout to an African 2Year-Old,” The New York times, 09-Aug-2014 [Online]. Available: http://www.nytimes.com/2014/08/10/world/africa/tracing-ebolasbreakout-to-an-african-2-year-old.html

[44] M. G. Dixon, I. J. Schafer, and Centers for Disease Control and Prevention (CDC), "Ebola viral disease outbreak--West Africa, 2014,” MMWR Morb. Mortal. Wkly. Rep., vol. 63, no. 25, pp. 548551, Jun. 2014.

[45] A. Menezes, "Faith Healer Helped Spread Ebola In Sierra Leone: Report,” International Business Times, 20-Aug-2014. [Online]. Available: http://www.ibtimes.com/faith-healer-helped-spreadebola-sierra-leone-report-1663694. [Accessed: 09-Nov-2014]

[46] Donald G. McNeil Jr. and Katarina Höije, "In Quick Response, Mali Thwarts an Ebola Outbreak," The New York times, 10-Nov$2014 \quad$ [Online]. Available: http://www.nytimes.com/2014/11/11/health/quick-response-andold-fashioned-detective-work-thwart-ebola-in-mali.html

[47] D. G. McNeil Jr., "Second Ebola Outbreak in Mali Eclipses Early Success,” The New York times, 12-Nov-2014 [Online]. Available: http://www.nytimes.com/2014/11/13/health/mali-reports-asecond-larger-ebola-outbreak.html?_r=0

[48] "CDC and Texas Health Department Confirm First Ebola Case Diagnosed in the U.S. | Press Release | CDC Online Newsroom | CDC." [Online]. Available: http://www.cdc.gov/media/releases/2014/s930-ebola-confirmedcase.html. [Accessed: 14-Nov-2014]

[49] L. Gambino and T. Dart, "US Ebola patient told staff of Liberia travel but was allowed to leave hospital,” the Guardian, 01-Oct2014. [Online]. Available: http://www.theguardian.com/world/2014/oct/01/ebola-us-doctorstexas-liberia. [Accessed: 14-Nov-2014]

[50] N. Allen, "First Ebola victim in America was sent home with antibiotics,” Telegraph.co.uk, 01-Oct-2014. [Online]. Available: http://www.telegraph.co.uk/news/worldnews/ebola/11132475/First -Ebola-victim-in-America-was-sent-home-with-antibiotics.html. [Accessed: 27-Oct-2014]

[51] C. Greg Botelho and Jacque Wilson, "Thomas Eric Duncan: First Ebola death in U.S," CNN. [Online]. Available: http://www.cnn.com/2014/10/08/health/thomas-eric-duncanebola/index.html. [Accessed: 27-Oct-2014]

[52] D. Kroll, "Dallas Nurse Who Cared For Duncan Contracts Ebola: 'Inadvertent Breach Of Protocol,’” Forbes, 12-Oct-2014. [Online]. Available:

http://www.forbes.com/sites/davidkroll/2014/10/12/dallas-nursewho-cared-for-duncan-contracts-ebola-inadvertent-breach-ofprotocol/. [Accessed: 27-Oct-2014]

[53] G. Lettis, "Ebola patient to be in high-level containment at NIH," WBALTV. [Online]. Available: http://www.wbaltv.com/health/ebola-patient-to-be-in-highlevelcontainment-at-nih/29187928. [Accessed: 27-Oct-2014]

[54] Catherine E. Shoichet, Josh Levs and Holly Yan, CNN, "Ebola patient flew on commercial jet; why didn’t anyone stop her?," CNN. [Online]. Available: http://www.cnn.com/2014/10/15/health/texas-ebolaoutbreak/index.html. [Accessed: 27-Oct-2014]

[55] B. M. Melanie Grayce West, "New York Ebola Patient to be Released from Hospital," WSJ Online Article, wsj.com, 10-Nov2014 [Online]. Available: http://online.wsj.com/articles/new-yorkebola-patient-to-be-released-from-hospital-1415659103

[56] "New York Doctor Just Back From Africa Has Ebola-NBC News,” NBC News, 23-Oct-2014. [Online]. Available: http://www.nbcnews.com/storyline/ebola-virus-outbreak/newyork-doctor-just-back-africa-has-ebola-n232561. [Accessed: 27Oct-2014]

[57] C. R.-M. Mike Stobbe, "Sierra Leone Surgeon With Ebola Coming To U.S. For Care,” The Huffington Post, 14-Nov-2014. [Online]. http://www.huffingtonpost.com/2014/11/14/sierra-leone-surgeonebola-us_n_6158288.html. [Accessed: 15-Nov-2014]

[58] C. Browne, X. Huo, P. Magal, M. Seydi, O. Seydi, and G. Webb, "A Model of the 2014 Ebola Epidemic in West Africa with Contact Tracing,” arXiv [q-bio.PE], 14-Oct-2014. 
[59] D. G. McNeil Jr., "Using a Tactic Unseen in a Century, Countries Cordon Off Ebola-Racked Areas," The New York times, 12-Aug2014 [Online]. Available: http://www.nytimes.com/2014/08/13/science/using-a-tacticunseen-in-a-century-countries-cordon-off-ebola-racked-areas.html

[60] S. Ng, N. E. Basta, and B. J. Cowling, "Association between temperature, humidity and ebolavirus disease outbreaks in Africa, 1976 to 2014,” Euro Surveill., vol. 19, no. 35, Sep. 2014 [Online]. Available: http://www.ncbi.nlm.nih.gov/pubmed/25210981

[61] D. G. Bausch and L. Schwarz, "Outbreak of ebola virus disease in Guinea: where ecology meets economy,” PLoS Negl. Trop. Dis., vol. 8, no. 7, p. e3056, Jul. 2014.

[62] J. E. Pinzon, J. M. Wilson, C. J. Tucker, R. Arthur, P. B. Jahrling, and P. Formenty, "Trigger events: enviroclimatic coupling of Ebola hemorrhagic fever outbreaks,” Am. J. Trop. Med. Hyg., vol. 71, no. 5, pp. 664-674, Nov. 2004.

[63] E. W. Taylor, "Selenium and viral diseases: Facts and hypotheses," J. Orthomol. Med., 1997 [Online]. Available: http://orthomolecular.org/library/jom/1997/pdf/1997-v12n04p227.pdf

[64] E. W. Taylor and C. S. Ramanathan, "Theoretical Evidence that the Ebola Virus Zaire Strain May Be Selenium-Dependent: A Factor in Pathogenesis and Viral Outbreaks?,” J. Orthomol. Med., 1995 [Online]. Available: http://www.orthomolecular.org/library/jom/1995/pdf/1995v10n0304-p131.pdf

[65] M. Harthill, "Review: micronutrient selenium deficiency influences evolution of some viral infectious diseases," Biol. Trace Elem. Res., vol. 143, no. 3, pp. 1325-1336, Dec. 2011.

[66] "Free Vector Graphic: Sun, Summer, Sunlight, Light, Rays-Free Image on Pixabay-99191.” [Online]. Available: http://pixabay.com/en/sun-summer-sunlight-light-rays-99191/. [Accessed: 14-Nov-2014]

[67] "Free Vector Graphic: Cloud, Rain, Drops, Drawing, Sky-Free Image on Pixabay-309469.” [Online]. Available: http://pixabay.com/en/cloud-rain-drops-drawing-sky-309469/. [Accessed: 14-Nov-2014]

[68] horse50, "Clipart-tango weather storm-outline.".

[69] pnx, "Clipart-Thermometer.".

[70] Magirly, "Clipart-Ebola Virus.”.

[71] "Free Vector Graphic: Twigs, Branches, Breaking Off, Man-Free Image on Pixabay-99208." [Online]. Available: http://pixabay.com/en/twigs-branches-breaking-off-man-99208/. [Accessed: 13-Nov-2014]

[72] rones, “Clipart-Icon Games.”.

[73] "Free Vector Graphic: Spade, Tools, Plant, Garden, Soil-Free Image on Pixabay-24434.” [Online]. Available: http://pixabay.com/en/spade-tools-plant-garden-soil-24434/. [Accessed: 13-Nov-2014]

[74] "Signs and Symptoms | Ebola Hemorrhagic Fever | CDC." [Online]. Available: http://www.cdc.gov/vhf/ebola/symptoms/index.html. [Accessed: 02-Nov-2014]

[75] "Ebola virus and Marburg virus Symptoms-Diseases and Conditions-Mayo Clinic.” [Online]. Available: http://www.mayoclinic.org/diseases-conditions/ebolavirus/basics/symptoms/con-20031241. [Accessed: 14-Nov-2014]

[76] "Ebola virus disease Information for Clinicians in U.S. Healthcare Settings | Ebola Hemorrhagic Fever | CDC.” [Online]. Available: http://www.cdc.gov/vhf/ebola/hcp/clinician-information-ushealthcare-settings.html. [Accessed: 14-Nov-2014]

[77] S. Fink, "Ebola's Mystery: One Boy Lives, Another Dies," The New York times, 09-Nov-2014 [Online]. Available: http://www.nytimes.com/2014/11/10/world/africa/the-capricioushand-of-ebola-one-boy-survives-as-othersdie.html?action=click\&contentCollection=US\%20Open\&region= Article\&module $=$ Promotron

[78] “Interim U.S. Guidance for Monitoring and Movement of Persons with Potential Ebola Virus Exposure | Ebola Hemorrhagic Fever | CDC." [Online]. Available: http://www.cdc.gov/vhf/ebola/exposure/monitoring-andmovement-of-persons-with-exposure.html. [Accessed: 02-Nov2014]

[79] "HAN Archive-00364|Health Alert Network (HAN)." [Online]. Available: http://www.bt.cdc.gov/han/han00364.asp. [Accessed: 27-Oct-2014]

[80] "Case Definition for Ebola Virus Disease (EVD) | Ebola Hemorrhagic Fever | CDC.” [Online]. Available: http://www.cdc.gov/vhf/ebola/hcp/case-definition.html. [Accessed: 27-Oct-2014]

[81] M. Saijo, M. Niikura, T. Ikegami, I. Kurane, T. Kurata, and S. Morikawa, "Laboratory diagnostic systems for Ebola and Marburg hemorrhagic fevers developed with recombinant proteins," Clin. Vaccine Immunol., vol. 13, no. 4, pp. 444-451, Apr. 2006.

[82] J. D. Kelly, "Make diagnostic centres a priority for Ebola crisis," Nature, vol. 513, no. 7517, p. 145, Sep. 2014.

[83] A. Roy, "The Dire Need For A Rapid Diagnostic Ebola Test In West Africa,” Forbes, 18-Sep-2014. [Online]. Available: http://www.forbes.com/sites/theapothecary/2014/09/18/the-direneed-for-a-rapid-diagnostic-ebola-test-in-west-africa/. [ Accessed: 27-Oct-2014]

[84] P. C. Iwen, P. W. Smith, A. L. Hewlett, C. J. Kratochvil, S. J. Lisco, J. N. Sullivan, S. G. Gibbs, J. J. Lowe, P. D. Fey, V. L. Herrera, A. R. Sambol, J. L. Wisecarver, and S. H. Hinrichs, "Safety Considerations in the Laboratory Testing of Specimens Suspected or Known to Contain Ebola Virus," Am J Clin Pathol [Online].

[85] "WHO | Clinical management of patients with viral haemorrhagic fever,” Sep. $2014 \quad$ [Online]. Available: http://www.who.int/csr/resources/publications/clinicalmanagement-patients/en/

[86] D. J. Funk and A. Kumar, "Ebola virus disease: an update for anesthesiologists and intensivists," Can. J. Anaesth., Nov. 2014 [Online].

[87] L. O. Gostin, D. Lucey, and A. Phelan, "The Ebola epidemic: a global health emergency,” JAMA, vol. 312, no. 11, pp. 1095-1096, Sep. 2014.

[88] L. O. Gostin, D. Lucey, and A. Phelan, "The Ebola epidemic: a global health emergency,” JAMA, vol. 312, no. 11, pp. 1095-1096, Sep. 2014.

[89] C. M. Gray, M. Addo, and R. E. Schmidt, "A dead-end host: is there a way out? A position piece on the Ebola virus outbreak by the International Union of Immunology Societies” [Online].

[90] J. L. Goodman, "Studying 'Secret Serums' -Toward Safe, Effective Ebola Treatments,” N. Engl. J. Med., vol. 371, no. 12, pp. 1086-1089, 2014.

[91] A. Blinder, "Atlanta Hospital Admits Second American With Ebola," The New York times, 05-Aug-2014 [Online]. Available: http://www.nytimes.com/2014/08/06/us/nancy-writebol-kentbrantly-ebola-atlanta.html

[92] A. Pollack, "Ebola Drug Could Save a Few Lives. But Whose?," The New York times, 08-Aug-2014 [Online]. Available: http://www.nytimes.com/2014/08/09/health/in-ebola-outbreakwho-should-get-experimental-drug.html

[93] L. A. Times, "Africans, three Ebola experts call for access to trial drug," latimes.com, 06-Aug-2014. [Online]. Available: http://www.latimes.com/world/africa/la-fg-three-ebola-expertsrelease-drugs-20140806-story.html. [Accessed: 12-Nov-2014]

[94] L. Oestereich, A. Lüdtke, S. Wurr, T. Rieger, C. Muñoz-Fontela, and S. Günther, "Successful treatment of advanced Ebola virus infection with T-705 (favipiravir) in a small animal model," Antiviral Res., vol. 105, pp. 17-21, May 2014.

[95] "French nurse cured of Ebola contracted in Liberia," MSN. [Online]. Available: http://www.msn.com/en$\mathrm{gb} /$ news/world/french-nurse-cured-of-ebola-contracted-inliberia/ar-BB7r1UJ. [Accessed: 12-Nov-2014]

[96] T. W. Geisbert, A. C. H. Lee, M. Robbins, J. B. Geisbert, A. N. Honko, V. Sood, J. C. Johnson, S. de Jong, I. Tavakoli, A. Judge, L. E. Hensley, and I. Maclachlan, "Postexposure protection of non-human primates against a lethal Ebola virus challenge with RNA interference: a proof-of-concept study,” Lancet, vol. 375, no. 9729, pp. 1896-1905, May 2010.

[97] A. Almendrala, "Here's A Breakdown Of The Ebola Treatments Used So Far In This Outbreak,” The Huffington Post, 15-Oct-2014. [Online].

http://www.huffingtonpost.com/2014/10/15/ebolatreatment_n_5990816.html. [Accessed: 12-Nov-2014]

[98] "Treatment of Ebola virus infection with brincidofovir." [Online]. Available: http://www.virology.ws/2014/10/09/treatment-ofebola-virus-infection-with-brincidofovir/. [Accessed: 14-Nov2014]

[99] Yazdan Yazdanpanah, Jose Ramon Arribas, Denis Malvy, "Treatment of Ebola virus disease-Springer." [Online].

[100] H. Evans, D. Slattery, and L. Mcshane, "Dr. Craig Spencer gets experimental anti-viral drug Brincidofovir to fight Ebola: officials,” NY Daily News. [Online]. Available: 
http://www.nydailynews.com/life-style/health/dr-craig-spencerexperimental-anti-viral-drug-brincidofovir-fight-ebola-officialsarticle-1.1986996. [Accessed: 12-Nov-2014]

[101] J. Gao and L. Yin, "Drug development for controlling Ebola epidemic-A race against time,” Drug Discov. Ther., vol. 8, no. 5, pp. 229-231, Oct. 2014.

[102] "Chimerix's Brincidofovir Has in Vitro Activity Against Ebola (NASDAQ:CMRX).” [Online]. Available: http://ir.chimerix.com/releasedetail.cfm?releaseid=868807. [Accessed: 15-Nov-2014]

[103] B. T. Services, "Use of Convalescent Whole Blood or Plasma Collected from Patients Recovered from Ebola Virus Disease for Transfusion, as an Empirical Treatment during Outbreaks" [Online].

Available: http://apps.who.int/iris/bitstream/10665/135591/1/WHO_HIS_SD S_2014.8_eng.pdf

[104] T. Burnouf, J. Emmanuel, D. Mbanya, M. El-Ekiaby, W. Murphy, S. Field, and J.-P. Allain, "Ebola: a call for blood transfusion strategy in sub-Saharan Africa,” Lancet, vol. 384, no. 9951, pp. 1347-1348, Oct. 2014.

[105] T. Hoenen, A. Groseth, and H. Feldmann, "Current ebola vaccines,” Expert Opin. Biol. Ther., vol. 12, no. 7, pp. 859-872, Jul. 2012.

[106] A. Marzi, F. Engelmann, F. Feldmann, K. Haberthur, W. L. Shupert, D. Brining, D. P. Scott, T. W. Geisbert, Y. Kawaoka, M. G. Katze, H. Feldmann, and I. Messaoudi, "Antibodies are necessary for rVSV/ZEBOV-GP-mediated protection against lethal Ebola virus challenge in nonhuman primates," Proc. Natl. Acad. Sci. U. S. A., vol. 110, no. 5, pp. 1893-1898, Jan. 2013.

[107] R. Kanapathipillai, A. M. H. Restrepo, P. Fast, D. Wood, C. Dye, M.-P. Kieny, and V. Moorthy, "Ebola Vaccine - An Urgent International Priority,” N. Engl. J. Med., vol. 0, no. 0, p. null.

[108] T. R. Frieden, I. Damon, B. P. Bell, T. Kenyon, and S. Nichol, "Ebola 2014--new challenges, new global response and responsibility,” N. Engl. J. Med., vol. 371, no. 13, pp. 1177-1180, Sep. 2014.

[109] "HAN Archive-00367|Health Alert Network (HAN)." [Online]. Available: http://emergency.cdc.gov/han/han00367.asp. [Accessed: 27-Oct-2014]

[110] "WHO | Infection prevention and control guidance for care of patients in health-care settings, with focus on Ebola," Sep. 2014 [Online]. Available: http://www.who.int/csr/resources/publications/ebola/filovirus_infe ction_control/en/

[111] "Infection Prevention and Control Recommendations for Hospitalized Patients with Known or Suspected Ebola Hemorrhagic Fever in U.S. Hospitals | Ebola Hemorrhagic Fever | CDC.” [Online]. Available: http://www.cdc.gov/vhf/ebola/hcp/infection-prevention-andcontrol-recommendations.html. [Accessed: 27-Oct-2014]

[112] Jeremy Ashkenas, Larry Buchanan, Joe Burgess, Hannah Fairfield, Denise Grady, Josh Keller, K.K. Rebecca Lai, Patrick J. Lyons,
Heather Murphy, Haeyoun Park, Sergio Peçanha, Archie Tse and Karen Yourish, "Ebola Facts: How Has the Food Supply Been Affected by the Outbreak?," 13-Nov-2014 [Online]. Available: http://www.nytimes.com/interactive/2014/07/31/world/africa/ebol a-virus-outbreak-qa.html?_r=0

[113] P. Torpiano and D. Pace, “Ebola: too far or so close?,” Malta Medical Journal, $2014 \quad$ [Online]. Available: http://www.um.edu.mt/umms/mmj/PDF/447.pdf

[114] "FACT SHEET: Emergency Funding Request to Enhance the U.S. Government's Response to Ebola at Home and Abroad," The White House. [Online]. Available: http://www.whitehouse.gov/the-press-office/2014/11/05/factsheet-emergency-funding-request-enhance-us-government-sresponse-eb. [Accessed: 15-Nov-2014]

[115] "Ebola Outbreaks 2000-2014 | Ebola Hemorrhagic Fever | CDC.” [Online]. Available: http://www.cdc.gov/vhf/ebola/outbreaks/history/summaries.html. [Accessed: 27-Oct-2014]

[116] "WHO | WHO Director-General briefs Geneva UN missions on the Ebola outbreak," Oct. 2014 [Online]. Available: http://www.who.int/dg/speeches/2014/ebola-briefing/en/

[117] L. Matowe, "Pharmacy can help fight against Ebola," Pharmaceutical Journal. [Online]. Available: http://www.pharmaceuticaljournal.com/opinion/comment/pharmacy-can-help-fight-againstebola/20066289.article. [Accessed: 27-Oct-2014]

[118] “2014 Ebola Outbreak in West Africa-Outbreak Distribution Map | Ebola Hemorrhagic Fever | CDC.” [Online]. Available: http://www.cdc.gov/vhf/ebola/outbreaks/2014-westafrica/distribution-map.html\#areas. [Accessed: 29-Oct-2014]

[119] "Outbreaks Chronology: Ebola Virus Disease | Ebola Hemorrhagic Fever | CDC.” [Online]. Available: http://www.cdc.gov/vhf/ebola/outbreaks/history/chronology.html. [Accessed: 29-Oct-2014]

[120] S. O. Foster and E. Gangarosa, "Passing the epidemiologic torch from Farr to the world. The legacy of Alexander D. Langmuir," Am. J. Epidemiol., vol. 144, no. 8 Suppl, pp. S65-73, Oct. 1996.

[121] L. O. Gostin, J. G. Hodge Jr, and S. Burris, "Is the United States Prepared for Ebola?,” JAMA, Oct. 2014 [Online].

[122] A. K. McElroy, B. R. Erickson, T. D. Flietstra, P. E. Rollin, S. T. Nichol, J. S. Towner, and C. F. Spiropoulou, "Biomarker correlates of survival in pediatric patients with ebola virus disease,” Emerg. Infect. Dis., vol. 20, no. 10, Oct. 2014 [Online].

[123] C. Byington, "Ebola and children: identifying and meeting their needs,” AAP News, Oct. 2014 [Online]. Available: http://aapnews.aappublications.org/content/early/2014/10/17/aapn ews.20141017-1.short

[124] "4th US aid worker with Ebola arrives in Atlanta," Yahoo News. [Online]. Available: http://news.yahoo.com/4th-us-citizen-ebolatreated-atlanta-070157340.html. [Accessed: 02-Nov-2014] 